\title{
Trade-offs and responsiveness of the
} single-layer urban canopy parametrization in WRF: an offline evaluation using the MOSCEM optimization algorithm and field observations

Article

Published Version

Loridan, T., Grimmond, C. S. B., Grossman-Clarke, S., Chen, F., Tewari, M., Manning, K., Martilli, A., Kusaka, H. and Best, M. (2010) Trade-offs and responsiveness of the single-layer urban canopy parametrization in WRF: an offline evaluation using the MOSCEM optimization algorithm and field observations. Quarterly Journal of the Royal Meteorological Society, 136 (649). pp. 997-1019. ISSN 1477-870X doi: https://doi.org/10.1002/qj.614 Available at https://centaur.reading.ac.uk/33537/

It is advisable to refer to the publisher's version if you intend to cite from the work. See Guidance on citing.

To link to this article DOI: http://dx.doi.org/10.1002/qj.614

Publisher: Wiley

All outputs in CentAUR are protected by Intellectual Property Rights law, 
including copyright law. Copyright and IPR is retained by the creators or other copyright holders. Terms and conditions for use of this material are defined in the End User Agreement.

\section{www.reading.ac.uk/centaur}

\section{CentAUR}

Central Archive at the University of Reading

Reading's research outputs online 


\title{
RMetS
}

Royal Meteorological Society

\section{Trade-offs and responsiveness of the single-layer urban canopy parametrization in WRF: An offline evaluation using the MOSCEM optimization algorithm and field observations}

\author{
Thomas Loridan, ${ }^{\text {a }}$ C. S. B. Grimmond, ${ }^{\mathrm{a}}$ Susanne Grossman-Clarke, ${ }^{\mathrm{b}}$ Fei Chen, ${ }^{\mathrm{c}}$ \\ Mukul Tewari, ${ }^{\mathrm{c}}$ Kevin Manning, ${ }^{\mathrm{c}}$ Alberto Martilli, ${ }^{\mathrm{d}}$ Hiroyuki Kusaka ${ }^{\mathrm{e}}$ and Martin Best ${ }^{\mathrm{f}}{ }^{\dagger}$ \\ ${ }^{\mathrm{a}}$ Environmental Monitoring and Modelling Group, Department of Geography, King's College London, London, UK \\ ${ }^{\mathrm{b}}$ Arizona State University, Tempe, USA \\ ${ }^{\mathrm{c}}$ National Center for Atmospheric Research, Boulder, Colorado, USA \\ ${ }^{\mathrm{d}}$ CIEMAT, Madrid, Spain \\ ${ }^{\mathrm{e} C e n t e r ~ f o r ~ C o m p u t a t i o n a l ~ S c i e n c e s, ~ U n i v e r s i t y ~ o f ~ T s u k u b a, ~ J a p a n ~}$ \\ ${ }^{\mathrm{f}}$ Met Office, Exeter, UK \\ ${ }^{\star}$ Correspondence to: Thomas Loridan, Environmental Monitoring and Modelling Group, Department of Geography, \\ King's College London, The Strand, London, WC2R 2LS, UK. E-mail: thomas.loridan@gmail.com \\ ${ }^{\dagger}$ The contribution of Martin Best was written during the course of his employment at the Met Office, UK and is published \\ with the permission of the Controller of HMSO and the Queen's Printer for Scotland
}

For an increasing number of applications, mesoscale modelling systems now aim to better represent urban areas. The complexity of processes resolved by urban parametrization schemes varies with the application. The concept of fitness-forpurpose is therefore critical for both the choice of parametrizations and the way in which the scheme should be evaluated. A systematic and objective model response analysis procedure (Multiobjective Shuffled Complex Evolution Metropolis (MOSCEM) algorithm) is used to assess the fitness of the single-layer urban canopy parametrization implemented in the Weather Research and Forecasting (WRF) model. The scheme is evaluated regarding its ability to simulate observed surface energy fluxes and the sensitivity to input parameters. Recent amendments are described, focussing on features which improve its applicability to numerical weather prediction, such as a reduced and physically more meaningful list of input parameters. The study shows a high sensitivity of the scheme to parameters characterizing roof properties in contrast to a low response to road-related ones. Problems in partitioning of energy between turbulent sensible and latent heat fluxes are also emphasized. Some initial guidelines to prioritize efforts to obtain urban land-cover class characteristics in WRF are provided. Copyright (c) 2010 Royal Meteorological Society and Crown Copyright.

Key Words: $\quad$ urban parametrization schemes; urban energy balance; urban canopy models; model evaluation; sensitivity analysis; parameter optimization

Received 28 August 2009; Revised 29 January 2010; Accepted 25 February 2010; Published online in Wiley InterScience 14 May 2010

Citation: Loridan T, Grimmond CSB, Grossman-Clarke S, Chen F, Tewari M, Manning K, Martilli A, Kusaka H, Best M. 2010. Trade-offs and responsiveness of the single-layer urban canopy parametrization in WRF: An offline evaluation using the MOSCEM optimization algorithm and field observations. Q. J. R. Meteorol. Soc. 136: 997-1019. DOI:10.1002/qj.614 


\section{Introduction}

With the ever-increasing computer resources available, complex mesoscale modelling systems able to simulate both the dynamics of the atmospheric flow and the main physical processes associated with it have flourished. The scale, resolution, and the type of processes they should be able to parametrize are determined by their application. A common feature in recent years, however, has been the realization that a better representation of urbanized areas is required. Given current resolutions, Numerical Weather Prediction (NWP), Air Quality Forecasting (AQF) and even Global Climate Models (GCM) now require an adequate parametrization of urban-atmosphere exchange (of heat, moisture, momentum or pollutants). This concern has been highlighted by recent efforts to include a separate representation of urban surfaces in operational NWP models (e.g. Taha, 1999; Masson, 2000; Chen et al., 2004; Best, 2005) or more recently in GCMs (Oleson et al., 2008a). Modelling systems designed for decision-making purposes (e.g. urban planning or climate-change mitigation strategies) or emergency response (e.g. toxic gas release from industrial leakage or terrorist activities, industrial fires) have further needs in terms of the physical processes to be modelled by an urban parametrization scheme (Baklanov et al., 2009).

The choice of scheme to include in a particular modelling system needs to be based on the targeted application; the methods and criteria to use for its evaluation should also be selected accordingly. The 'fitness-for-purpose' guidance presented by Baklanov et al. (2009) illustrates such a concern and a number of application-dependent components to consider in model evaluation can be linked to that concept:

- Firstly, there is consideration of the requirements of the model. The type and amount of input information on which the parametrization is based should enable a representation of the urban canopy features relevant for the application and yet be consistent with the data realistically procurable at the scale resolved. A similar compromise arises between the level of detail with which processes should be modelled (numerical resolution, scale of processes parametrized) and the cost in computing time.

- Secondly, there is assessment of how the model performs relative to the changes in parameter values. In order to accurately represent the diversity of constraints that urban environments impose on the atmospheric flow, a significant model response to changes in its input is desirable. However, the degree of sensitivity to a particular input should be linked to the level of uncertainty inherent to its estimation at the grid scale: excessive sensitivity is to be avoided when input parameter values are not procurable with a matching accuracy.

- Thirdly, there is performance of the model as compared to observations. To ensure that the evaluation procedure is relevant to the targeted application, measurement campaigns should be specifically designed to collect observations at a scale similar to the one resolved, while on the other hand model simulations need to be set up to reproduce the conditions during the campaign. Similarly, only an application-dependent set of statistics can provide an objective picture of the model's performance.
In this study, focus is given to the land surface and urban parametrization schemes in the Weather Research and Forecasting (WRF) model designed for NWP purposes. Their primary function is to simulate outgoing energy fluxes which act as lower boundary conditions for a parent atmospheric model. Hence, estimation of the surface energy balance in each grid cell classified as urban arises as a main requirement. The surface energy balance (SEB) as introduced by Oke (1978) and restated more fully by Offerle et al. $(2005,2006)$ provides the adequate framework in which to evaluate the scheme's performance:

$$
Q^{*}+Q_{\mathrm{F}}=Q_{\mathrm{H}}+Q_{\mathrm{E}}+\Delta Q_{\mathrm{S}}+\Delta Q_{\mathrm{A}}+S \quad\left(\mathrm{~W} \mathrm{~m}^{-2}\right)
$$

$Q^{*}$ is the net all-wave radiation which combines the net short-wave $\left(K^{*}\right)$ and net long-wave $\left(L^{*}\right)$ contributions both resulting from a balance between their incoming $(K \downarrow, L \downarrow)$ and outgoing $(K \uparrow, L \uparrow)$ components:

$$
Q^{*}=K^{*}+L^{*}=(K \downarrow-K \uparrow)+(L \downarrow-L \uparrow) .
$$

$Q_{F}$ is the anthropogenic heat flux, $Q_{H}$ turbulent sensible heat flux, $Q_{\mathrm{E}}$ turbulent latent heat flux and $\Delta Q_{\mathrm{S}}$ net storage heat flux. The net horizontal advection flux $\Delta Q_{\mathrm{A}}$ is usually dealt with by three-dimensional (3-D) models rather than land surface schemes which typically represent a single column of atmosphere. When integrated as part of an NWP modelling system, the horizontal dimension of such a column corresponds to a grid cell while its vertical extent is defined by the height of the first atmospheric level. Being explicitly resolved by the parent atmospheric model, advection is therefore only represented above the column. The $S$ term accounts for all other possible sources and sinks of energy, including for instance heat removed by rainfall runoff or photosynthetic heat (Offerle et al., 2006). Currently, these are not usually modelled within urban parametrization schemes designed for NWP purposes and are by definition not measured.

The ability of such schemes to account for the large energy storage in the urban fabric, the trapping of incoming radiation in street canyons and the enhancement of turbulent processes due to an increased urban roughness represents the main challenge. Although no ideal approach has yet been objectively identified (Grimmond et al., 2010), three categories can be listed (Masson, 2006): (1) empirical models reproducing measured features of the urban energy balance using statistical approaches, (2) Land Surface Models (LSM) initially developed for vegetated surfaces and modified to account for the specificities of urban environments, and (3) Urban Canopy Models (UCM) which represent the next level of complexity and take into account the urban morphology. A further subdivision of categories (2) and (3) is introduced with regards to whether the schemes simulate the vertical stress distribution inside the urban canopy to account for a momentum drag on the atmospheric flow (multi-layer schemes, e.g. Martilli et al., 2002).

Designed for mesoscale forecasting purposes, the level of detail which can be modelled by such schemes is by nature restricted: running time and consequently grid resolution have limits dictated by the need to produce a forecast in time. A scheme fit for NWP purpose would hence describe the urban morphology, roughness, radiative and thermal 
properties with a set of parameters meaningful at the scale of a model grid box. Ideally, the set of understandable inputs should be kept small and procurable from a systematic procedure (e.g. geographic information database, remote sensing or image processing techniques). The response of the scheme to parameter changes needs to be coherent with the accuracy of their estimation, especially when default land-cover classes are used to characterize the urban grid cells in the modelled domain.

Evaluating the performance and sensitivity of urban parametrization schemes as part of a complete NWP modelling system is a complex task due to both the limited control available on the fields directly forcing the scheme and possible error compensation phenomena occurring between the different components of the system. For instance, the NWP model bias in surface radiation fluxes would directly impact our assessment of how well the urban parametrization is able to represent the SEB. As a consequence, thorough studies of model performance and sensitivity are best performed with a decoupled or 'offline' version of the scheme where the parent atmospheric model is removed (Masson et al., 2002). This does not permit any assessment of the importance of advection nor of potential interactions occurring between neighbouring cells but ensures that the scheme is evaluated on its own.

Observations of the forcing fields $(K \downarrow, L \downarrow$ plus common meteorological fields) at a height above the roughness sublayer (Roth, 2000) are provided as a substitute to the parent atmospheric model's outputs. Measurements of the surface energy balance fluxes at a scale compatible with that of a grid box (e.g. the local or neighbourhood scale as defined in Grimmond and Oke (2002)) are also needed to enable a direct evaluation of the scheme's outgoing fluxes, along with an extensive survey of input parameter values characterizing the footprint area of the measurements (Grimmond, 2006).

In this paper, we introduce an objective and systematic procedure to evaluate model response using the Multiobjective Shuffled Complex Evolution Metropolis (MOSCEM) algorithm of Vrugt et al. (2003). The methodology is applied to the single-layer urban canopy parametrization (Kusaka et al., 2001) implemented in the WRF model (Skamarock et al., 2005), using hourly data from a measurement campaign in Marseille (Grimmond et al., 2004; Lemonsu et al., 2004). The applicability for NWP purposes of the main parametrizations implemented as part of the scheme is assessed, and some modifications are introduced where needed. It is anticipated that these amendments will be suitable for other applications; for example, providing the meteorological conditions for air quality forecasting. The scheme performance is analysed in terms of the quality of the surface energy balance flux simulations, and the utility of the model response analysis method as a tool providing guidelines for the refinement of WRF land-cover classes is underlined.

\section{Systematic and objective model response analysis using the MOSCEM algorithm}

When trying to quantify the sensitivity to input parameter values, offline models are run iteratively usually, perturbing a set of selected parameters at each step (Sellers and Dorman, 1987; Arnfield and Grimmond, 1998; Kawai et al., 2007; Oleson et al., 2008b). The impact on the model's outputs, often illustrated by statistical measures comparing simulated and observed fields, is then seen as an indicator of how the model responds to a particular parameter change. Designed for the automatic calibration of hydrological models, the Multiobjective Shuffled Complex Evolution Metropolis (MOSCEM) algorithm of Vrugt et al. (2003) provides a systematic and unbiased tool for such a purpose. Of particular interest is its ability to: (1) objectively sample the entire parameter space rather than a discrete predefined set of values, and (2) optimize with respect to several criteria (multi-objective optimization), thereby providing some insight into the trade-offs which control the modelled SEB (multi-objective optimization identifies situations where improving one criteria is possible only at the expense of another: Gupta et al., 1998; Khu and Madsen, 2005; Confesor and Whittaker, 2007; Shafii and De Smedt, 2009). The tradeoff surfaces, composed of all parameter values leading to an optimum compromise in the performance of the modelled fluxes, are referred to as Pareto fronts to highlight the nonuniqueness of the solution (Yapo et al., 1998). They are approximated by MOSCEM using a Markov Chain Monte Carlo sampler, designed to avoid the grouping of the solution in a subspace of the Pareto front, and deal with the strong correlation between parameters which typically occurs in land surface models (Vrugt et al., 2003).

The algorithm iteratively updates a set of model input parameters while minimizing several optimization criteria (objective functions) which here are the Root Mean Square Errors (RMSE) for $Q^{*}, Q_{H}$ and $Q_{E}$. The set-up of a MOSCEM run requires each parameter to be given a default value and limits between which it can evolve. To be as objective as possible, wide ranges that are physically meaningful should be specified. This will increase the convergence time of the algorithm, but ensures that the model response to any type of value change is accounted for. Default values should be objectively determined in an attempt to reproduce the conditions in which the evaluation and forcing data were measured.

For a comprehensive analysis of the model response, only one parameter is optimized at a time while all others are kept at their default values. MOSCEM then randomly initializes $s$ samples ( $s$ different sets of parameter values spread out in the parameter space) and iteratively updates their values towards $s$ optimized samples minimizing the RMSE of the fluxes (details of the algorithm are provided in Vrugt et al. (2003)). For some of the parameters only a Pareto set of solutions emerges, showing that no optimum state can be objectively identified. Others provide an optimum value for which all fluxes reach their minimum RMSE (see Figure 6, panels 1 and 4, for illustration of the two behaviours when only two fluxes are considered). For the latter, a measure of the model response to the parameter optimized can be derived when subtracting the RMSE from a default run of the model (all parameters being set to their default) to the one obtained with the optimized value. Ideally, the resulting $\triangle$ RMSE would be negative for all fluxes, indicating an improvement of all objectives. For parameters triggering some trade-offs, at least one of the $\triangle$ RMSE will stay positive for any value change along the Pareto front. It is possible to assess the model response for a particular flux by selecting the value leading to the best improvement for this flux (lowest $\triangle \mathrm{RMSE}$ ). The trade-off effects are measurable from the impact a value change along the Pareto front has on the RMSE. Like all sensitivity analyses, the procedure is a function of what is chosen as default. In the unlikely 
situation of a near-zero RMSE, the responsiveness would appear difficult to analyse.

This procedure is designed to analyse how the model behaves with regards to a change in one of its inputs and does not intend to identify the optimum values of all model parameters leading to the best or minimum RMSE. Calibration of the scheme for a particular site would require an optimization of all parameters simultaneously, hence complicating our understanding of each parameter's influence. The use of MOSCEM to perform such a multiparameter optimization would however provide an efficient method to derive the default values for urban land-cover classes, and will be considered for future studies.

Repeating the procedure for all parameters, an objective model-sensitivity-ranking can be obtained in terms of the RMSE improvements $\left(\triangle \mathrm{RMSE}<0 \mathrm{~W} \mathrm{~m}^{-2}\right)$ for each of the fluxes considered $\left(Q^{*}, Q_{H}\right.$ and $\left.Q_{E}\right)$. Such a ranking is to be accompanied by a trade-off effect ranking $\left(\triangle \mathrm{RMSE}>0 \mathrm{~W} \mathrm{~m}^{-2}\right.$ ) for all parameters leading to a Pareto front of solutions. This procedure (Figure 1), presents how the model responds to any parameter change and therefore provides a very powerful tool to: (1) identify the parameters to which the modelling of each flux is most sensitive, (2) sort out the ones which do not significantly affect the model performance, and (3) highlight potential trade-offs in the modelling of the SEB. From such knowledge, urban parametrization schemes can be adapted to better fit NWP requirements. Figure 2 summarizes the procedure applied to the Single-Layer Urban Canopy Model implemented in WRF (SLUCM: Kusaka et al., 2001; Chen et al., 2010).

\section{The single-layer urban canopy model in WRF}

The single-layer urban canopy parametrization in WRF results from a coupling between the Noah land surface model (Chen and Dudhia, 2001) and the Single Layer Urban Canopy Model (Kusaka et al., 2001; Kusaka and Kimura, 2004) using a tile approach. This prevents any interaction between the two components, since each scheme is run separately and their output fluxes are weighted according to the relative portion of the grid cell considered urbanized $\left(f_{\text {urb }}\right)$ :

$$
Q_{\mathrm{GRID}}=Q_{\mathrm{SLUCM}} \times f_{\mathrm{urb}}+Q_{\mathrm{Noah}} \times\left(1-f_{\mathrm{urb}}\right)
$$

where $Q_{\mathrm{GRID}}$ is the grid-averaged value of an outgoing flux $\left(K \uparrow, L \uparrow, Q^{*}, Q_{H}\right.$ or $\left.Q_{E}\right), Q_{\text {SLUCM }}$ and $Q_{\text {Noah }}$ refer to the scheme's modelled fluxes.

First introduced in WRFv2.2 (June 2006), the SLUCM was initially implemented with the same set of parametrizations as formulated by Kusaka and Kimura (2004). Table I summarizes the main input requirements of this on-line version of the scheme along with the key terms they impact. Ambiguities arise as to how many of the required site parameters should be specified. For example, a user planning to refine the default WRF parameter values for a particular site would be left to estimate the normalized canyon height $\left(Z_{\text {norm }}\right)$ and width $\left(C_{\text {norm }}\right)$, the normalized roof width $\left(R_{\text {norm }}\right)$, the drag coefficient by building $\left(C_{\mathrm{DB}}\right)$, their volumetric parameter $\left(B_{\mathrm{V}}\right)$ or the roughness lengths (for heat and momentum) of roof surfaces and the canyon space $\left(Z_{0 \mathrm{R}}, Z_{0 \mathrm{HR}}, Z_{0 \mathrm{C}}, Z_{0 \mathrm{HC}}\right)$. In addition, without care it is also possible to change individual parameters values without appropriately changing others (e.g. canyon roughness length independent from its geometry). In an attempt to: (1) clarify the physical meaning of input parameters, (2) add consistency between the various parametrizations involved, and (3) take into account the complexity of parameter estimation at the scale of a model grid box, several modifications were made to this initial version (Table II). Some of these changes have already been implemented in WRF v3.1 (March 2009), all others are planned for next release $(\mathrm{v} 3.2,2010)$

The fundamental unit of the SLUCM is the 2-D canyon (Figure 3), which is best described with reference to its height and the width of its street and roof before any normalization occurs (i.e. from mean average values of building height and roof/street widths at the local scale). From these dimensions many of the previously required inputs can be calculated internally ensuring that if individual characteristics are changed, all others which should change are also appropriately recalculated (Table II). It allows fundamental Geographic Information System (GIS) data to be directly usable without requiring interpretation as to what parameters might be, although the choice of an adequate technique to derive areally averaged values of $Z_{\mathrm{R}}$, $W_{\text {road }}$ and $W_{\text {roof }}$ at the selected scale (e.g. $1 \mathrm{~km} \times 1 \mathrm{~km}$ model grid box) is still left to the user.

The portion of canyon surfaces covered by walls, roads and roofs are normalized internally by the total width $\left(W_{\text {roof }}+W_{\text {road }}\right)$ to provide the $F_{\text {walls }}, F_{\text {roof }}$ and $F_{\text {road }}$ fractions (Table II, Eqs 13-15) which determine the contribution each type of surface has on the fluxes from the SLUCM (i.e. as in Table I, Eq. 5):

$$
Q_{\text {SLUCM }}=F_{\text {roof }} Q_{\text {roof }}+F_{\text {walls }} Q_{\text {walls }}+F_{\text {road }} Q_{\text {road }} .
$$

The building's plan area fraction $\left(\lambda_{\mathrm{P}}\right)$ and frontal area index $\left(\lambda_{\mathrm{F}}\right)$ characterizing the building morphometry (Grimmond and Oke, 1999) are linked respectively to $F_{\text {roof }}$ and the normalized building height $Z_{\text {norm }}$ (Table II, Eq. 16). The original relations for the view factors (Table I, Eqs 1-4) required to represent the trapping of radiation inside an infinitely long canyon (i.e. 2-D canyon) are kept. They now depend on $F_{\text {road }}, F_{\text {walls }}$ and $Z_{\text {norm }}$ which are unambiguously linked to the specified canyon geometry:

$$
\begin{aligned}
& \Phi_{\text {wall } \rightarrow \text { sky }}=\frac{2}{N} \sum_{k=1}^{N} \\
& \left\{\frac{1}{4}\left(1+\frac{Z_{\text {norm }}-\frac{d_{z}}{2}-k d_{z}}{\sqrt{\left(Z_{\text {norm }}-\frac{d_{z}}{2}-k d_{z}\right)^{2}+F_{\text {road }}^{2}}}\right)\right\} \\
& \Phi_{\text {road } \rightarrow \text { sky }}=1-\left(\frac{F_{\text {walls }}}{F_{\text {road }}}\right) \Phi_{\text {wall } \rightarrow \text { sky }} ; \\
& \Phi_{\text {wall } \rightarrow \text { road }}=\Phi_{\text {wall } \rightarrow \text { sky }} ; \\
& \Phi_{\text {wall } \rightarrow \text { wall }}=1-\left(\Phi_{\text {wall } \rightarrow \text { sky }}+\Phi_{\text {wall } \rightarrow \text { road }}\right) .
\end{aligned}
$$

Given additional input information on the albedo and emissivities of materials, the net radiative budget at each canyon surface can be computed.

For turbulent fluxes $\left(Q_{H}, Q_{E}\right)$ Monin-Obukhov similarity theory is applied to characterize the turbulent exchange coefficients above the roof and canyon space where turbulent energy transfer is likely to happen due to strong temperature gradients (Masson, 2000). Further inputs are needed to represent the roughness of both the roof and 


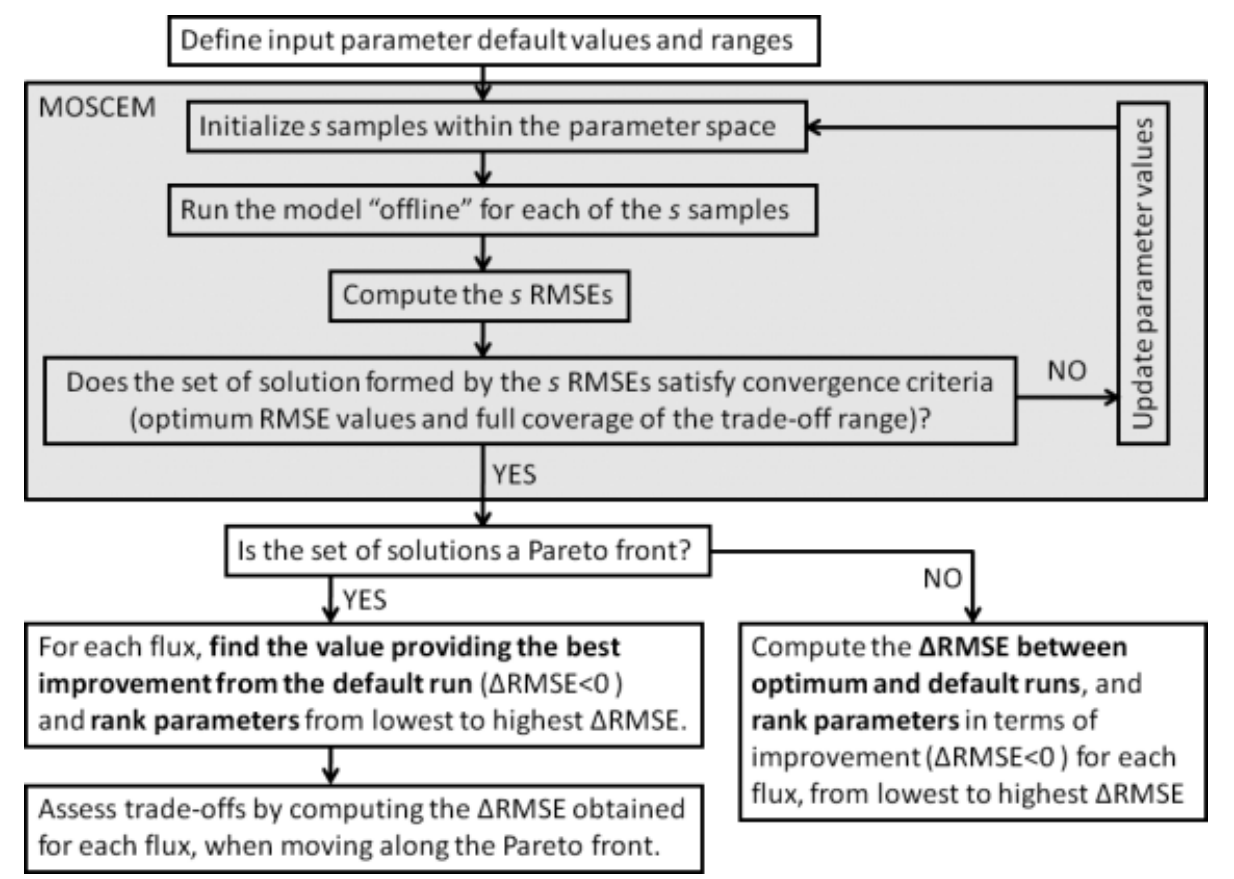

Figure 1. Flow chart of the model response analysis using the MOSCEM algorithm.

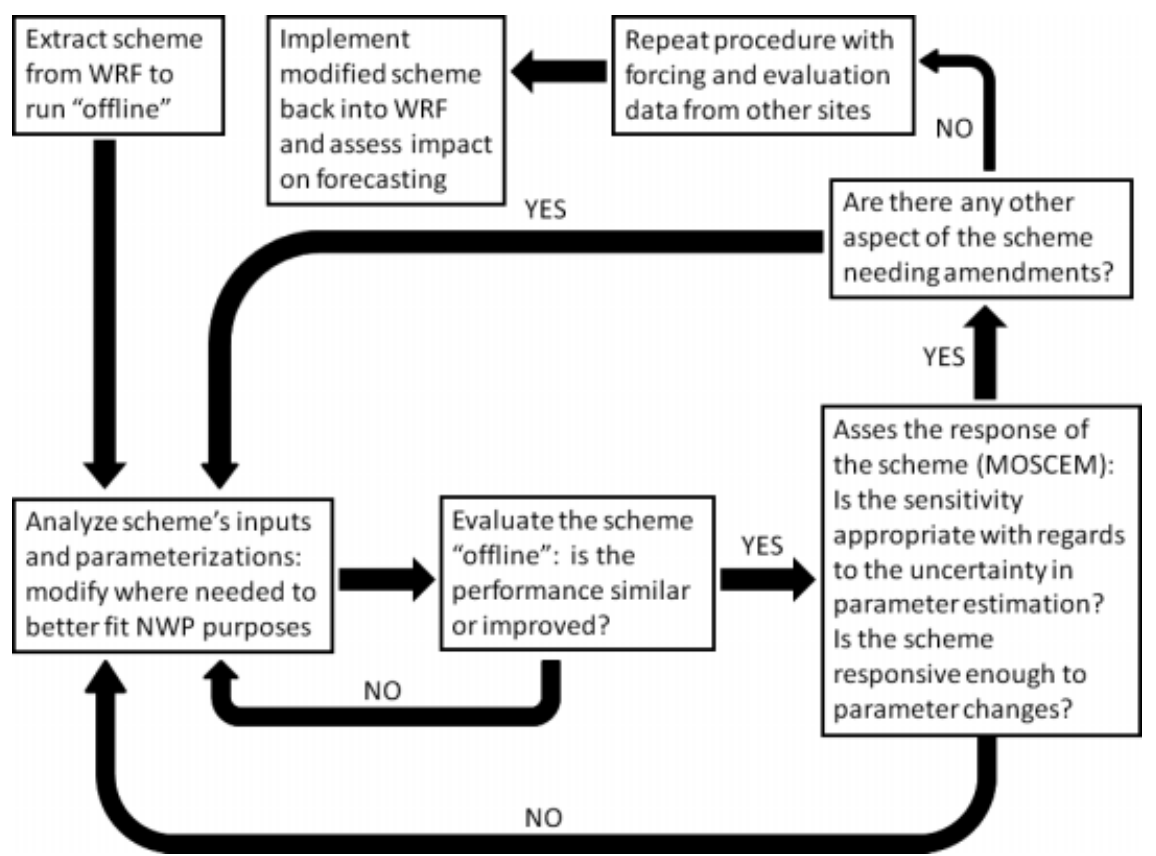

Figure 2. Flow chart of the procedure applied to improve the applicability of the Noah/SLUCM.

canyon. The canyon roughness length for momentum $Z_{0 \mathrm{C}}$ and corresponding zero-plane displacement height $Z_{\mathrm{D}}$ are now parametrized as a function of the canyon geometry (Table II, Eq. 18: MacDonald et al., 1998), using a value of $C_{\mathrm{d}}=1.2$ for the drag coefficient, $\kappa=0.4$ for von Kármán's constant and $\alpha_{\mathrm{m}}=4.43, \beta_{\mathrm{m}}=1.0$ for the two empirical parameters required (MacDonald et al., 1998; Grimmond and Oke, 1999; Kastner-Klein and Rotach, 2004). Given the strong sensitivity to the input value of $Z_{0 \mathrm{R}}$ (Loridan et al., 2009) and the inherent complexity in its estimation at the scale required for NWP, a new approach based on the formulation of MacDonald et al. (1998) is proposed for its parametrization in future releases of WRF: it is adapted to take into account the variability in roof height using a modified frontal area index $\lambda_{\mathrm{F}, \sigma}$ based on the standard deviation of building height $\sigma_{Z}$ (Table II, Eqs 19, 20). Consequently $Z_{0 \mathrm{R}}$ is removed from the list of input and replaced by new parameter $\sigma_{Z}$ which is physically more relevant at the scale of a model grid cell and can be obtained from an urban Digital Elevation Model (DEM) or GIS, satellite imagery or aerial photographs (e.g. Ratti et al., 2002). Variability in roof geometry has been shown to be a predominant factor in turbulence above the urban canopy layer (Rafailidis, 1997; Kastner-Klein and Rotach, 2004; Xie et al., 2008).

Knowledge of the turbulent exchanges from wall and road surfaces is needed to characterize both the temperature and humidity of the air inside the canyon. These are derived from Jurges' formula (Kusaka et al., 2001) that directly 


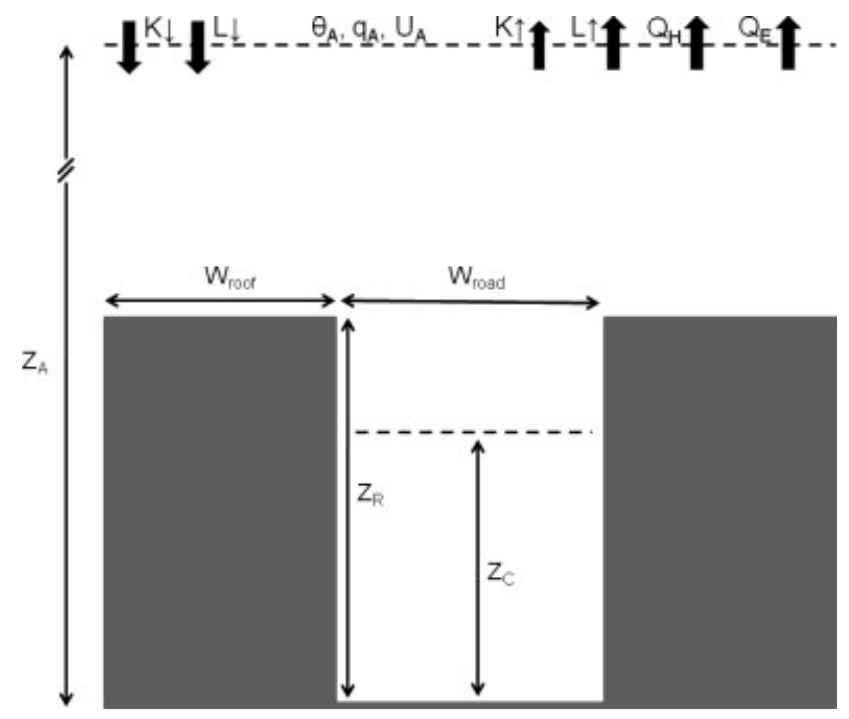

Figure 3. Schematic of the 2-D canyon structure used in WRF/SLUCM. See text for symbol definitions.

links the exchange coefficients to the wind velocity. Being a single-layer model, the SLUCM does not explicitly compute the wind profile down to street level. Instead a logarithmic profile is assumed from the forcing level $\left(Z_{\mathrm{A}}\right)$ down to the roof $\left(Z_{\mathrm{R}}\right)$, with an exponential decrease to a height $Z_{\mathrm{C}}$ inside the canyon (Table I, Eq. 10). The corresponding wind velocity $\left(U_{\mathrm{C}}\right)$ is therefore parametrized as a function of its forcing value $\left(U_{\mathrm{A}}\right)$ and the roof-level value $\left(U_{\mathrm{R}}\right)$. The attenuation coefficient $(a)$ in the exponential equation uses Inoue's (1963) parametrization developed for vegetation canopies and was originally adapted for application in urban areas using two input parameters: a drag coefficient by building and a building volumetric capacity (Table I, Eq. 11). These two parameters are now removed and the attenuation coefficient is derived from an urban morphology relation (Table II, Eq. 21) using available parameters (Coceal and Belcher, 2004; Di Sabatino et al., 2008).

Bulk transfer equations are used to model the turbulent fluxes of heat $\left(Q_{\mathrm{H}}\right)$ and moisture $\left(Q_{\mathrm{E}}\right)$ in both Noah and the SLUCM:

$$
\begin{aligned}
Q_{\mathrm{H}-S} & =-\rho c_{p} C_{\mathrm{H}} U_{A}\left(\theta_{A}-\theta_{S}\right) \\
Q_{\mathrm{E}-S} & =-\rho L_{\mathrm{V}} C_{\mathrm{E}} U_{A}\left(q_{A}-q_{S}\right)
\end{aligned}
$$

$Q_{H-S}$ and $Q_{E-S}$ are generic notations which apply to the turbulent exchanges of energy above natural surfaces, roof surfaces or the canyon space. Subscript $S$ refers to the surface considered, and $A$ to the atmospheric forcing value of either the potential temperature $(\theta)$ or the specific humidity $(q)$. $\rho$ is the density of air, $c_{p}$ the specific heat, and $L_{V}$ the latent heat of vaporization. The turbulent exchange coefficients $C_{\mathrm{H}}$ and $C_{\mathrm{E}}$ are based on Monin-Obukhov similarity theory (Table I, Eqs 6-8) and are assumed identical in both the Noah and SLUCM schemes (Table I, Eq. 6). The nondimensional functions for momentum and heat in stable cases originally differed from one scheme to another. To improve the coherence between the two formulations the Paulson (1970) equations as implemented in Noah were substituted into the SLUCM (Table II, Eqs 22, 23). However, since the ratio of roughness length for momentum to heat is considerably larger over urbanized surfaces than vegetated ones (Voogt and Grimmond, 2000), a specific approach to the modelling of $Z_{0 \mathrm{HR}}$ and $Z_{0 \mathrm{HC}}$ needs to be taken for the SLUCM. The relation derived by Kanda et al. (2007) using an outdoor scale model and evaluated against field data is chosen because it was developed specifically for urban conditions and has recently been applied to the Simple Urban Energy Balance Model for Mesoscale Simulations (SUMM), which is very similar to the SLUCM in its approach (Kanda et al., 2005; Kawai et al., 2009). It links the roughness length for heat to that for momentum using the roughness Reynolds number and an empirical constant $a_{\mathrm{K}}$ (Table II, Eqs 24, 25). The formula is applied to both the roof surfaces and canyon space using the best-fit value of $a_{\mathrm{K}}=1.29$ identified by Kanda et al. (2007) as well as two distinct values of the roughness Reynolds number (Table II, Eq. 26). In Noah, the Zilitinkevich (1995) approach is used to parametrize this ratio over vegetated surfaces with a default $C_{\text {ZIL value of } 0.1}$ (WRF 3.1: Chen et al., 1997):

$$
\begin{aligned}
Z_{0 \mathrm{H}, \mathrm{veg}} & =Z_{0, \mathrm{veg}} \exp \left(-\kappa C_{\mathrm{ZIL}} \sqrt{\mathrm{Re}_{\mathrm{veg}}^{*}}\right) \\
\operatorname{Re}_{\mathrm{veg}}^{*} & =\frac{u^{*} Z_{0, \mathrm{veg}}}{v}
\end{aligned}
$$

where $Z_{0 \text {,veg }}$ and $Z_{0 \mathrm{H} \text {,veg }}$ respectively represent the roughness length for momentum and heat and $\mathrm{Re}_{\mathrm{veg}}$ * the roughness Reynolds number over vegetated surfaces. The recently formulated $C_{\mathrm{ZIL}}$ as a function of vegetation canopy height (Chen and Zhang, 2009) is not used here.

Altogether these modifications have resulted in a reduction of seven input parameters. The two main contributions are: (1) a smaller list of more physically meaningful inputs, and (2) more consistency in the main parametrizations involved in the SLUCM as they are now explicitly linked to the canyon geometry. The on-line implementation of the scheme directly benefits from both aspects.

\section{Performance compared to observations from Marseille}

This version of Noah/SLUCM, after modifications (Table II), is evaluated 'offline' using hourly data from Marseille (Grimmond et al., 2004; Lemonsu et al., 2004). The evaluation focuses on the ability to simulate $Q^{*}, Q_{\mathrm{H}}, Q_{\mathrm{E}}$ (and $\left.\Delta Q_{S}\right)$ as these are key to incorporating urban areas for NWP purposes. These results are the base or control simulation used as a reference in the model response analysis presented in section 5 .

\subsection{The campaign}

Both the forcing fields required to drive the model and SEB fluxes are available for a 26-day period in summer (16 June to 12 July 2001 - Day of year (DOY) 167 to 193). Instruments were mounted on an adjustable pneumatic tower installed on the roof of a $20 \mathrm{~m}$ high building in the city centre of Marseille $\left(43^{\circ} 17^{\prime} \mathrm{N}, 5^{\circ} 23^{\prime} \mathrm{E}\right)$, leading to measurements at two distinct heights: 34.6 and $43.9 \mathrm{~m}$ above street level (Grimmond et al., 2004; Roberts et al., 2006). The measurement system (composed of a sonic anemometer, an open path gas analyser and a net radiometer) allows a direct observation of: $Q^{*}, Q_{H}$ and $Q_{E}$.

The anthropogenic contribution to these fluxes is also sensed by the instruments and therefore needs to be 
Table I. Key parameters required by the SLUCM in its original online version (WRF v2.2).

\begin{tabular}{|c|c|c|}
\hline $\begin{array}{l}\text { SLUCM parameters in } \\
\text { WRF v2.2 }\end{array}$ & Main parametrization in which they are involved & Definition of symbols \\
\hline $\begin{array}{l}\text { Normalized roof height: } \\
Z_{\text {norm }} \\
\text { Normalized roof width: } \\
R_{\text {norm }} \\
\text { Normalized canyon width: } \\
C_{\text {norm }}\end{array}$ & $\begin{array}{l}\Phi_{\text {wall } \rightarrow \text { sky }}=\frac{2}{N} \sum_{k=1}^{N} \\
\left\{\frac{1}{4}\left(1+\frac{Z_{\text {norm }}-\frac{d_{z}}{2}-k d_{z}}{\sqrt{\left(Z_{\text {norm }}-\frac{d_{z}}{2}-k d_{z}\right)^{2}+R_{\text {norm }}{ }^{2}}}\right)\right\} \\
\Phi_{\text {road } \rightarrow \text { sky }}=1-\left(\frac{2 Z_{\text {norm }}}{R_{\text {norm }}}\right) \Phi_{\text {wall } \rightarrow \text { sky }} \quad(2) \\
\Phi_{\text {wall } \rightarrow \text { road }}=\Phi_{\text {wall } \rightarrow \text { sky }}(3) \\
\Phi_{\text {wall } \rightarrow \text { wall }}=1-\left(\Phi_{\text {wall } \rightarrow \text { sky }}+\Phi_{\text {wall } \rightarrow \text { road }}\right)\end{array}$ & $\begin{array}{l}\Phi_{\text {wall } \rightarrow \text { sky }}, \Phi_{\text {road } \rightarrow \text { sky }}, \Phi_{\text {wall } \rightarrow \text { road }}, \\
\Phi_{\text {wall } \rightarrow \text { wall }}: \\
\text { wall to sky, road to sky, wall to } \\
\text { road and wall to wall view factors. } \\
N: \text { iteration limit }(N=100) \\
d_{z}=Z_{\text {norm }} /(N+1) \text { : integration } \\
\text { step when moving down the wall }\end{array}$ \\
\hline
\end{tabular}

Partitioning of SLUCM fluxes:

$$
\begin{aligned}
Q_{\text {SLUCM }}=R_{\text {norm }} Q_{\text {roof }}+ & 2 Z_{\text {norm }} Q_{\text {walls }} \\
& +C_{\text {norm }} Q_{\text {road }}
\end{aligned}
$$

QsLucm, Q roof, $Q_{\text {walls, }}$ Q Q generic notation for any of the outgoing fluxes from the SLUCM, the roof, the walls or the road.

Canyon roughness length for heat and momentum: $Z_{0 \mathrm{C}}, Z_{0 \mathrm{HC}}$

Canyon zero plane displacement height: $Z_{\mathrm{D}}$

$$
\begin{aligned}
& C_{\mathrm{H}}=C_{\mathrm{E}}=\frac{\kappa^{2}}{\psi_{\mathrm{m}} \psi_{\mathrm{h}}} \\
& \psi_{\mathrm{m}}=\int_{\varsigma_{0, \mathrm{~m}}}^{\varsigma} \frac{\varphi_{\mathrm{m}}}{\varsigma^{\prime}} d \varsigma^{\prime} ; \quad \psi_{\mathrm{h}}=\int_{\varsigma_{0, \mathrm{~h}}}^{\varsigma} \frac{\varphi_{\mathrm{h}}}{\varsigma^{\prime}} d \varsigma^{\prime} \quad(7) \\
& \varsigma=\frac{\left(Z_{\mathrm{A}}+Z_{0 \mathrm{C}}\right)-Z_{\mathrm{D}}}{L} ; \quad \varsigma_{0, \mathrm{~m}}=\frac{Z_{0 \mathrm{C}}}{L} ; \quad \varsigma_{0, \mathrm{~h}}=\frac{Z_{0 \mathrm{HC}}}{L}
\end{aligned}
$$

$\varphi_{\mathrm{m}}, \varphi_{\mathrm{h}}$ : Dyer and Hicks (1970) in unstable conditions $(\varsigma<0)$, and Kondo et al. (1978) in stable conditions $(\varsigma>0)$.
$C_{\mathrm{H}}, C_{\mathrm{E}}$ : turbulent exchange coefficients for heat and moisture

$\kappa$ : von Kármán's constant.

$\Psi_{\mathrm{m}}, \Psi_{\mathrm{h}}$ : integrated universal functions for momentum and heat

$\varphi_{\mathrm{m}}, \varphi_{\mathrm{h}}$ : non-dimensional gradients for momentum and heat $Z_{\mathrm{A}}$ : first atmospheric level (forcing level).

L: Obukhov length
Roof roughness length for heat and momentum: $Z_{0 \mathrm{R}}$, $Z_{\text {OHR }}$

$\begin{array}{ll} & \varsigma=\frac{\left(Z_{\mathrm{A}}+Z_{0 \mathrm{R}}\right)-Z_{\mathrm{D}}}{L} ; \quad \varsigma_{0, \mathrm{~m}}=\frac{Z_{0 \mathrm{R}}}{L} ; \quad \varsigma_{0, \mathrm{~h}}=\frac{Z_{0 \mathrm{HR}}}{L} \\ \text { Mean roof height: } Z_{\mathrm{R}} & \text { Wind profile: }\end{array}$

Drag coefficient by
building: $C_{\mathrm{DB}}$
Building volumetric capac-
ity: $B_{\mathrm{V}}$

$$
U_{\mathrm{C}}=U_{\mathrm{R}} \mathrm{e}^{-a\left(1-\frac{Z_{\mathrm{C}}}{Z_{\mathrm{R}}}\right)} ; \quad U_{\mathrm{R}}=U_{\mathrm{A}} \frac{\ln \left(\frac{Z_{\mathrm{R}}-Z_{\mathrm{D}}}{Z_{0 \mathrm{C}}}\right)}{\ln \left(\frac{Z_{\mathrm{A}}-Z_{\mathrm{D}}}{Z_{0 \mathrm{C}}}\right)}
$$

$$
a=Z_{\mathrm{R}}\left(\frac{C_{\mathrm{DB}} B_{\mathrm{V}}}{2 l_{\mathrm{m}}^{2}}\right)^{\frac{1}{3}} ; \quad l_{\mathrm{m}}=\kappa\left(Z_{\mathrm{R}}-Z_{\mathrm{D}}\right)
$$

$U_{\mathrm{C}}$ : wind velocity at level $Z_{\mathrm{C}}=$ $0.7 Z_{\mathrm{R}}$ inside the canyon.

$U_{\mathrm{A}}$ : wind velocity at forcing level $\left(Z_{\mathrm{A}}\right), U_{\mathrm{R}}$ : at roof level $\left(\mathrm{Z}_{\mathrm{R}}\right)$. $a$ : attenuation coefficient (Inoue, 1963)

$l_{\mathrm{m}}$ : mixing length 
Table II. Changes made to the WRF/SLUCM.

\begin{tabular}{lc}
\hline Modification/Implication & Description \\
\hline $\begin{array}{l}\text { Canyon height, width and roof } \\
\text { width are read as input }\end{array}$ & Input: $Z_{\mathrm{R}}, W_{\text {road }}$ and $W_{\text {roof }}(\mathrm{m})$ \\
$\begin{array}{l}\text { Canyon geometry inputs now } \\
\text { with a clear physical meaning. }\end{array}$ & \\
\hline $\begin{array}{l}\text { Normalized ratios are derived } \\
\text { from canyon geometry }\end{array}$ & $Z_{\text {norm }}=Z_{R} /\left(W_{\text {roof }}+W_{\text {road }}\right)$ \\
& $F_{\text {walls }}=2 Z_{\text {norm }}=2 Z_{\mathrm{R}} /\left(W_{\text {roof }}+W_{\text {road }}\right)$ \\
& $F_{\text {roof }}=W_{\text {roof }} /\left(W_{\text {roof }}+W_{\text {road }}\right)$ \\
& $F_{\text {road }}=W_{\text {road }} /\left(W_{\text {roof }}+W_{\text {road }}\right)$
\end{tabular}

Definition of symbols

$Z_{\mathrm{R}}$ : roof height

$W_{\text {road }}$ : road width

$W_{\text {roof }}$ : roof width (Figure 3 )

$F_{\text {walls }}, F_{\text {roof }}$ and $F_{\text {road }}$ normalized fraction of canyon surfaces covered by walls, roof and road.

removed from list of inputs.

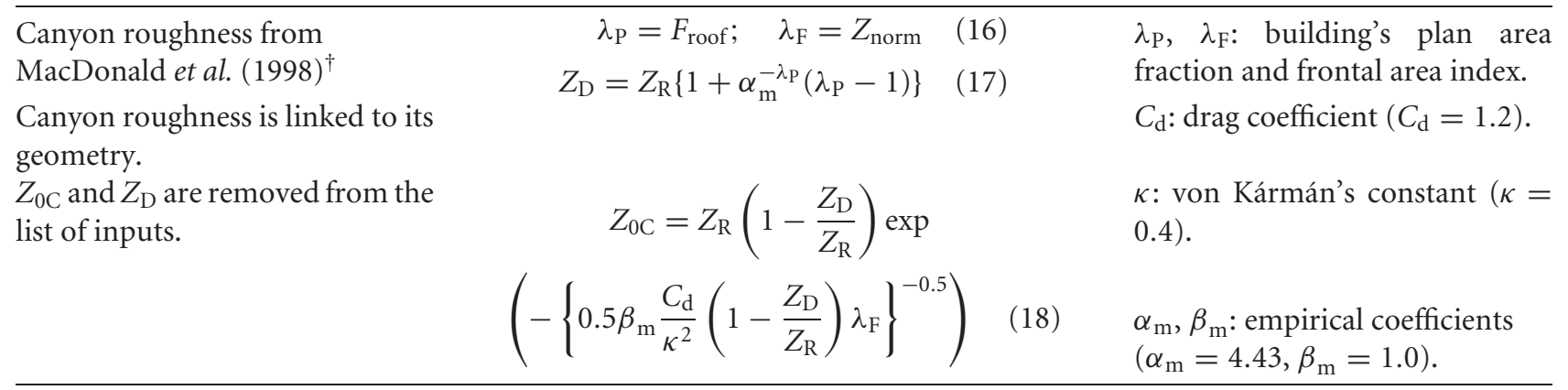

Roof roughness $\left(Z_{0 \mathrm{R}}\right)$ parameterized using the standard deviation of building height $\left(\sigma_{Z}\right)$.

$$
\begin{gathered}
\lambda_{\mathrm{F}, \sigma}=\sigma_{Z} /\left(W_{\text {roof }}+W_{\text {road }}\right) ; \\
\sigma_{Z}=\max \left(\sigma_{Z}, \sigma_{Z \text { min }}\right) \\
Z_{0 \mathrm{R}}=Z_{\mathrm{R}}\left(1-\frac{Z_{\mathrm{D}}}{Z_{\mathrm{R}}}\right) \exp \\
\left(-\left\{0.5 \beta_{\mathrm{m}} \frac{C_{\mathrm{d}}}{\kappa^{2}}\left(1-\frac{Z_{\mathrm{D}}}{Z_{\mathrm{R}}}\right) \lambda_{\mathrm{F}, \sigma}\right\}^{-0.5}\right)
\end{gathered}
$$

$Z_{0 \mathrm{R}}$ is removed from the list of inputs, $\sigma_{\mathrm{Z}}$ is introduced instead.
$\sigma_{Z}$ : standard deviation of building height

$\sigma_{Z \text { min }}$ : minimum value for $\sigma_{Z}$ (currently set to $1 \mathrm{~m}$ )

$\lambda_{\mathrm{F}, \sigma}:$ modified frontal area index based on $\sigma_{Z}$.

Attenuation coefficient in wind profile as a function of known quantities only ${ }^{\dagger}$

$C_{\mathrm{DB}}$ and $B_{\mathrm{V}}$ are removed from the list of inputs.

$$
a=\frac{\kappa Z_{\mathrm{R}}}{l_{\mathrm{m}} \ln \left(\frac{Z_{\mathrm{R}}-Z_{\mathrm{D}}}{Z_{0 \mathrm{C}}}\right)} ; \quad l_{\mathrm{m}}=\kappa\left(Z_{\mathrm{R}}-Z_{\mathrm{D}}\right)
$$

See Table I

Change of non-dimensional functions in the SLUCM for stable conditions: Paulson (1970) formulations are now implemented as in Noah (Chen et al., 1997) Same turbulence routine now used in both schemes.

$$
\varphi_{\mathrm{m}}(\varsigma)=\left\{\begin{array}{lc}
1+5 \varsigma & 0<\varsigma<1 \\
(1-16 \varsigma)^{-\frac{1}{4}}-5<\varsigma<0
\end{array}\right.
$$

$$
\varphi_{\mathrm{h}}(\varsigma)= \begin{cases}\varphi_{\mathrm{m}} & 0<\varsigma<1 \\ \varphi_{\mathrm{m}}^{2} & -5<\varsigma<0\end{cases}
$$
momentum to heat from Kanda et al. (2007)

$$
\begin{aligned}
& Z_{0 \mathrm{HC}}=Z_{0 \mathrm{C}} \exp \left(2.0-a_{\mathrm{K}}\left(\operatorname{Re}_{\mathrm{C}}^{*}\right)^{0.25}\right) \\
& Z_{0 \mathrm{HR}}=Z_{0 \mathrm{R}} \exp \left(2.0-a_{\mathrm{K}}\left(\operatorname{Re}_{\mathrm{C}}^{*}\right)^{0.25}\right) \\
& \operatorname{Re}_{\mathrm{C}}^{*}=\frac{u^{*} Z_{0 \mathrm{C}}}{v} ; \quad \operatorname{Re}_{\mathrm{R}}^{*}=\frac{u^{*} Z_{0 \mathrm{R}}}{v}
\end{aligned}
$$

\section{See Table I}

from the list of inputs. Empirical coefficient $a_{\mathrm{K}}$ is introduced. $a_{\mathrm{K}}$ : empirical constant from Kanda et al. (2007)

$\operatorname{Re}_{\mathrm{R}}{ }^{*}, \mathrm{Re}_{\mathrm{C}}{ }^{*}$ : roughness Reynolds number for roof and canyon. $u^{*}$ : friction velocity (at level $Z_{\mathrm{A}}$ )

$v$ : molecular diffusivity of the air.

\footnotetext{
$\dagger$ - were included in WRF release v3.1.
} 
taken into account. Using measurements of $\mathrm{CO}_{2}$ fluxes as an indication of human activity in the area, Grimmond et al. (2004) estimated $Q_{\mathrm{F}}$ to vary between a night-time value of $15 \mathrm{~W} \mathrm{~m}^{-2}$ and a daytime one of $50 \mathrm{~W} \mathrm{~m}^{-2}$, with two peaks (1000 and 1900, Local Standard Time) to a value of $75 \mathrm{~W} \mathrm{~m} \mathrm{~m}^{-2}$ during the transition periods (see profile Figure 7(b)).

In a related study using data from the meso- $\mathrm{NH}$ mesoscale model and two intensive observation periods (21-23 and 24-26 June), Pigeon et al. (2007) have shown that for a particular set of synoptic conditions (e.g. sea breeze or Mistral wind) the contribution of advection to these fluxes can be of considerable importance. However, the lack of adequate measurements over the entire 26-day period of the campaign does not permit the inclusion of $\Delta Q_{\mathrm{A}}$ in the present analysis (Grimmond et al., 2004). The SLUCM simulates the SEB fluxes at a reference level $\left(Z_{\mathrm{A}}\right)$ corresponding to the measurement height. Turbulent fluxes of heat $\left(Q_{H}\right)$ and moisture $\left(Q_{E}\right)$, modelled without any advection component, are evaluated against observed fluxes including such contributions. This presents a limitation to offline analysis but corresponds to what would occur within the WRF modelling system since the SLUCM does not deal with advection below its forcing level. This shortcoming of the urban parametrization would be sensed in the lower boundary fluxes provided to the atmospheric component of WRF at the first vertical level in the same way that it is in the current offline analysis. Following a similar argument, the S term is not modelled by the SLUCM and therefore omitted from the present offline model evaluation.

The 'observed' storage heat is then estimated as a residual, closing the energy balance:

$$
\Delta Q_{\mathrm{S}}=\left(Q^{*}+Q_{\mathrm{F}}\right)-\left(Q_{\mathrm{H}}+Q_{\mathrm{E}}\right)
$$

Although such a method is only one of several alternatives, its applicability to the current data is confirmed by Roberts et al. (2006): using a subset of the same Marseille dataset (from 4 to 11 July - DOY 185 to 192), three additional independent methods to estimate $\Delta Q_{S}$ were analysed in their study. They demonstrate good agreement with the energy balance residual method selected here. Given the set of assumptions previously described this residual storage heat implicitly takes into account the contributions from the $S$ and $\Delta Q_{\mathrm{A}}$ terms. As for $Q_{\mathrm{H}}$ and $Q_{\mathrm{E}}$, the modelled and observed values of $\Delta Q_{S}$ will consequently not rigorously represent the same quantities since none of these contributions is modelled by the SLUCM. This however corresponds to its conditions of use in the on-line mode.

All measurements, independent of environment, have errors associated with them (Lee et al., 2004; Grimmond, 2006; Foken, 2008a). These are linked to instrument siting and operation, fetch, or processing of data, and energy balance closure is rarely observed. There is some evidence that the scale of patchiness of the surface may influence the ability to obtain closure (Wilson et al., 2002; Foken 2008b).

\subsection{Model parameters and variables}

To set up an offline run of the Noah/SLUCM for the site of Marseille, a total of 68 parameters require an input value (30 for the SLUCM, 37 for Noah and one for the coupling: the urban fraction), while 11 state variables need to be initialized ( 3 for SLUCM, 8 for Noah). Model runs performed at the same location with the Town Energy Balance (TEB) model (Lemonsu et al., 2004; Roberts et al., 2006) and the Soil Model for Sub-Mesoscales, Urbanized version (SM2-U: Dupont and Mestayer, 2006) were used as a reference to gather this information. Both models are very similar to the SLUCM in their approach and most of the urban values required were therefore available in the corresponding publications. For Noah, the default values corresponding to the 'mixed shrubland/grassland' vegetation class as implemented in WRF and a 'clay/loam' soil as documented in Chen and Dudhia (2001) were used which corresponds to the natural surfaces used by Dupont and Mestayer (2006) in their simulations (i.e. trees and shrub with a clay-loam soil). Most of these default values are listed in Table III.

Hourly data of incoming short- and long-wave radiation ( $K \downarrow$ and $L \downarrow)$, air temperature, relative humidity, wind components and pressure are interpolated to a 10-minute time step for forcing. This is the longest time step that ensures there are no numerical instabilities from the turbulence scheme (e.g. oscillations between stability regimes). The hourly profile of anthropogenic heat estimated by Grimmond et al. (2004) is added to the sensible heat flux from the SLUCM at each step and the net storage heat is computed as a residual of the total (modelled) energy balance. The grid-averaged output fluxes $\left(Q^{*}, Q_{H}\right.$, $Q_{E}$ and $\Delta Q_{S}$ ) for the first 10 minutes of each hour are used for evaluation against the hourly observed data. With such a setting the model state variables (and in particular the material surface temperatures) are updated every 10 minutes and the fluxes are evaluated as close as possible to the time step when the forcings are provided, to align with the observations.

Figure 4 shows the time series of the modelled and observed SEB fluxes for the entire simulation period and the corresponding diurnal means and standard deviations, plus scatter plots with regression lines. Statistics commonly used in the field (Willmott, 1982; Jacobson, 1999; Grimmond et al., 2010) are reported in Table IV to quantify the model performance for all hours, daytime (from $2 \mathrm{~h}$ after $K \downarrow>0 \mathrm{~W} \mathrm{~m} \mathrm{~m}^{-2}$ to $2 \mathrm{~h}$ before $K \downarrow=0 \mathrm{~W} \mathrm{~m}^{-2}$ ), night-time (from $2 \mathrm{~h}$ after $K \downarrow=0 \mathrm{~W} \mathrm{~m}^{-2}$ to $2 \mathrm{~h}$ before $K \downarrow>0 \mathrm{~W} \mathrm{~m}^{-2}$ ) and transition periods (remaining time periods).

For $Q^{*}$, a systematic underestimation of the observed fluxes for all time periods is easily identified from the mean diurnal evolution (Figure 4(e)), as well as the relative position of the linear regression and 1:1 lines (Figure 4(i)). The high negative Mean Bias Errors (MBE) reported in Table IVa also confirm this trend. As the systematic portion of the root-mean-square error $\left(\mathrm{RMSE}_{\mathrm{S}}\right)$ is larger than the unsystematic $\left(\operatorname{RMSE}_{\mathrm{U}}\right)$, this suggests underestimation is likely attributable to the model itself or the choice of default parameter values, and could potentially be improved. For $Q_{\mathrm{H}}$ on the other hand, overall and daytime $\mathrm{RMSE}_{\mathrm{U}}$ are considerably larger than the $\mathrm{RMSE}_{S}$, meaning that the majority of the error is linked to the spread of the observed data. Yet night-time and transition values of the RMSE $E_{S}$ are dominant, hinting at some issues with the modelling of $\mathrm{Q}_{\mathrm{H}}$ under weak turbulent forcing. A daytime timing issue can also be identified in the mean diurnal evolution (Figure 4(f)) with a morning value larger than the observation and an evening one smaller. The simulated values of $Q_{E}$ are underestimated for all time periods, and the large $\mathrm{RMSE}_{\mathrm{S}}$ 
Table III. Input parameters selected for analysis of model response.

\begin{tabular}{|c|c|c|c|c|c|c|}
\hline & Parameter & Min. & Max. & Default & Parameter Definition & Reference for default \\
\hline 1 & $Z_{\mathrm{R}}$ & 12.6 & 18.6 & 15.6 & Roof height (m) & LE04 \\
\hline 2 & $W_{\text {roof }}$ & 11.2 & 31.2 & 21.2 & Roof width (m) & LE04 \\
\hline 3 & $W_{\text {road }}$ & 3.6 & 15.6 & 9.6 & Road width $(\mathrm{m})$ & LE04 \\
\hline 4 & $\sigma_{Z}$ & 1.0 & 15.0 & 9.0 & Standard deviation of roof height $(\mathrm{m})$ & - \\
\hline 5 & $a_{\mathrm{K}}$ & 0.5 & 2.0 & 1.29 & $\begin{array}{l}\text { Empirical coefficient from Kanda } \\
\text { et al. (2007) }\end{array}$ & KA07 \\
\hline 6 & $\alpha_{\text {roof }}$ & 0.05 & 0.4 & 0.22 & Roof albedo $(-)$ & LE04 and DM06 \\
\hline 7 & $\alpha_{\text {wall }}$ & 0.05 & 0.55 & 0.20 & Wall albedo $(-)$ & LE04 and DM06 \\
\hline 8 & $\alpha_{\text {road }}$ & 0.05 & 0.25 & 0.08 & Road albedo $(-)$ & LE04 and DM06 \\
\hline 9 & $\varepsilon_{\text {roof }}$ & 0.85 & 0.98 & 0.90 & Roof emissivity $(-)$ & LE04 and DM06 \\
\hline 10 & $\varepsilon_{\text {wall }}$ & 0.85 & 0.98 & 0.90 & Wall emissivity $(-)$ & LE04 and DM06 \\
\hline 11 & $\varepsilon_{\text {road }}$ & 0.85 & 0.98 & 0.94 & Road emissivity $(-)$ & LE04 and DM06 \\
\hline 12 & $k_{\text {roof }}$ & 0.19 & 1.5 & 0.90 & $\begin{array}{l}\text { Conductivity of roof materials } \\
\left(\mathrm{W} \mathrm{m} \mathrm{m}^{-1} \mathrm{~K}^{-1}\right)\end{array}$ & $\mathrm{RO} 06$ \\
\hline 13 & $k_{\text {wall }}$ & 0.09 & 2.3 & 0.55 & $\begin{array}{l}\text { Conductivity of wall materials } \\
\left(\mathrm{W} \mathrm{m}{ }^{-1} \mathrm{~K}^{-1}\right)\end{array}$ & $\mathrm{RO} 06$ \\
\hline 14 & $k_{\text {road }}$ & 0.03 & 2.1 & 1.77 & $\begin{array}{l}\text { Conductivity of road materials } \\
\left(\mathrm{W} \mathrm{m}{ }^{-1} \mathrm{~K}^{-1}\right)\end{array}$ & $\mathrm{RO} 06$ \\
\hline 15 & $C_{\text {roof }}$ & $0.6 \times 10^{6}$ & $2.3 \times 10^{6}$ & $1.77 \times 10^{6}$ & $\begin{array}{l}\text { Heat capacity of roof materials } \\
\left(\mathrm{J} \mathrm{m}^{-3} \mathrm{~K}^{-1}\right)\end{array}$ & $\mathrm{RO} 06$ \\
\hline 16 & $C_{\text {wall }}$ & $0.4 \times 10^{6}$ & $2.3 \times 10^{6}$ & $1.67 \times 10^{6}$ & $\begin{array}{l}\text { Heat capacity of wall materials } \\
\left(\mathrm{J} \mathrm{m}^{-3} \mathrm{~K}^{-1}\right)\end{array}$ & $\mathrm{RO} 06$ \\
\hline 17 & $C_{\text {road }}$ & $0.3 \times 10^{6}$ & $2.3 \times 10^{6}$ & $1.89 \times 10^{6}$ & $\begin{array}{l}\text { Heat capacity of road materials } \\
\left(\mathrm{J} \mathrm{m}^{-3} \mathrm{~K}^{-1}\right)\end{array}$ & $\mathrm{RO} 06$ \\
\hline 18 & $d_{z, \text { roof }}$ & 0.05 & 0.5 & 0.32 & Total thickness of roof layers (m) & RO06 \\
\hline 19 & $d_{z, \text { wall }}$ & 0.1 & 1.0 & 0.26 & Total thickness of wall layers (m) & RO06 \\
\hline 20 & $d_{z, \text { road }}$ & 0.5 & 2.0 & 1.24 & Total thickness of road layers (m) & RO06 \\
\hline 21 & $d_{z \text { frac,roof }}(1)$ & 0.02 & 0.1 & 0.062 & Fraction of $d_{z \text {,roof }}$ covered by layer 1 & RO06 \\
\hline 22 & $d_{z \text { frac,roof }}(2)$ & 0.1 & 0.49 & 0.468 & Fraction of $d_{z \text {,roof }}$ covered by layer 2 & RO06 \\
\hline 23 & $d_{z \text { frac,roof }}(3)$ & 0.1 & 0.4 & 0.375 & Fraction of $d_{z, \text { roof }}$ covered by layer 3 & RO06 \\
\hline 24 & $d_{z \text { frac,wall }}(1)$ & 0.02 & 0.1 & 0.038 & Fraction of $d_{z \text {,wall }}$ covered by layer 1 & RO06 \\
\hline 25 & $d_{z \text { frac,wall }}(2)$ & 0.1 & 0.3 & 0.154 & Fraction of $d_{z, \text { wall }}$ covered by layer 2 & RO06 \\
\hline 26 & $d_{z \text { frac,wall }}(3)$ & 0.1 & 0.59 & 0.577 & Fraction of $d_{z, \text { wall }}$ covered by layer 3 & RO06 \\
\hline 27 & $d_{z \text { frac,road }}(1)$ & 0.02 & 0.1 & 0.032 & Fraction of $d_{z \text {,road }}$ covered by layer 1 & RO06 \\
\hline 28 & $d_{z \text { frac,road }}(2)$ & 0.1 & 0.4 & 0.16 & Fraction of $d_{z \text {,road }}$ covered by layer 2 & RO06 \\
\hline 29 & $d_{z \text { frac,road }}(3)$ & 0.1 & 0.49 & 0.4 & Fraction of $d_{z \text {,road }}$ covered by layer 3 & RO06 \\
\hline 30 & $f_{\text {urb }}$ & 0.764 & 0.964 & 0.864 & Urban fraction $(-)$ & LE04 \\
\hline 31 & $R_{\mathrm{cmin}}$ & 40 & 400 & 170 & Stomatal resistance $\left(\mathrm{s} \mathrm{m}^{-1}\right)$ & CD01 (+DM06) \\
\hline 32 & $R_{\mathrm{gl}}$ & 30 & 100 & 100 & Radiation stress parameter $(-)$ & CD01 (+DM06) \\
\hline 33 & $h_{\mathrm{S}}$ & 36.25 & 54.56 & 39.18 & Vapour pressure deficit parameter $(-)$ & CD01 (+DM06) \\
\hline 34 & $\alpha_{\mathrm{veg}}$ & 0.10 & 0.30 & 0.23 & Vegetation albedo $(-)$ & CD01 (+DM06) \\
\hline 35 & $\varepsilon_{\mathrm{veg}}$ & 0.88 & 0.97 & 0.93 & Vegetation emissivity $(-)$ & CD01 (+DM06) \\
\hline 36 & $Z_{0 \text {, veg }}$ & 0.03 & 1.6 & 0.05 & $\begin{array}{l}\text { Roughness length for momentum of } \\
\text { vegetation }(\mathrm{m})\end{array}$ & CD01 (+DM06) \\
\hline 37 & $\Theta_{\mathrm{s}}$ & 0.339 & 0.476 & 0.465 & $\begin{array}{l}\text { Maximum soil moisture content } \\
\left(\mathrm{m}^{3} \mathrm{~m}^{-3}\right)\end{array}$ & CD01 (+DM06) \\
\hline 38 & $\Theta_{\text {ref }}$ & 0.236 & 0.453 & 0.382 & $\begin{array}{l}\text { Reference soil moisture content } \\
\left(\mathrm{m}^{3} \mathrm{~m}^{-3}\right)\end{array}$ & CD01 (+DM06) \\
\hline 39 & $\Theta_{\mathrm{w}}$ & 0.010 & 0.2 & 0.103 & Wilting point $\left(\mathrm{m}^{3} \mathrm{~m}^{-3}\right)$ & CD01 (+DM06) \\
\hline 40 & $\Theta_{\text {dry }}$ & 0.010 & 0.2 & 0.103 & Dry soil moisture content $\left(\mathrm{m}^{3} \mathrm{~m}^{-3}\right)$ & CD01 (+DM06) \\
\hline 41 & LAI & 1.0 & 5.0 & 3.0 & Leaf Area Index $\left(\mathrm{m}^{3} \mathrm{~m}^{-3}\right)$ & CD01 (+DM06) \\
\hline 42 & $f_{\mathrm{V}}$ & 0.1 & 0.8 & 0.7 & Green vegetation fraction $(-)$ & CD01 (+DM06) \\
\hline 43 & QTZ & 0.10 & 0.92 & 0.35 & Soil quartz content $(-)$ & CD01 (+DM06) \\
\hline 44 & $C_{\text {soil }}$ & $0.5 \times 10^{6}$ & $4.0 \times 10^{6}$ & $1.26 \times 10^{6}$ & Soil heat capacity $\left(\mathrm{J} \mathrm{m}^{-3} \mathrm{~K}^{-1}\right)$ & CD01 (+DM06) \\
\hline 45 & $C_{\mathrm{ZIL}}$ & 0.01 & 1.0 & 0.1 & Zilitinkevitch parameter & $\mathrm{CH} 97$ \\
\hline
\end{tabular}

Default values are from: Lemonsu et al., 2004 (LE04), Dupont and Mestayer, 2006 (DM06), Roberts et al., 2006 (RO06), Kanda et al., 2007 (KA07), Chen and Dudhia, 2001 (CD01) and Chen et al., 1997 (CH97). 
(a)

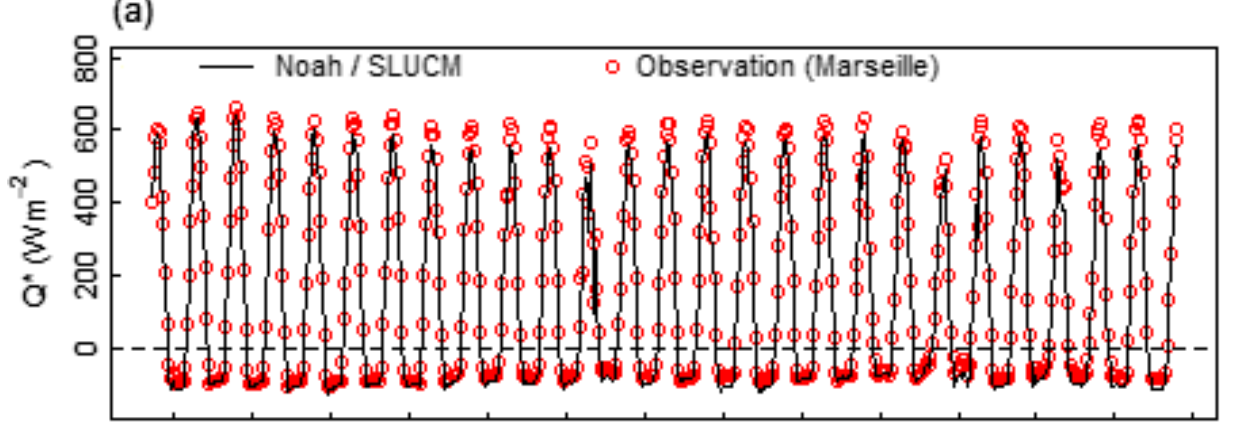

(b)

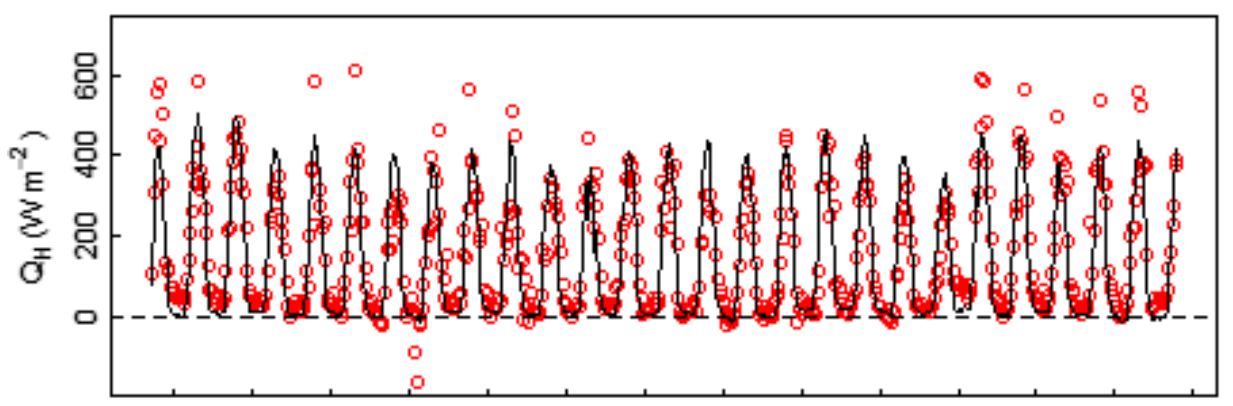

(c)

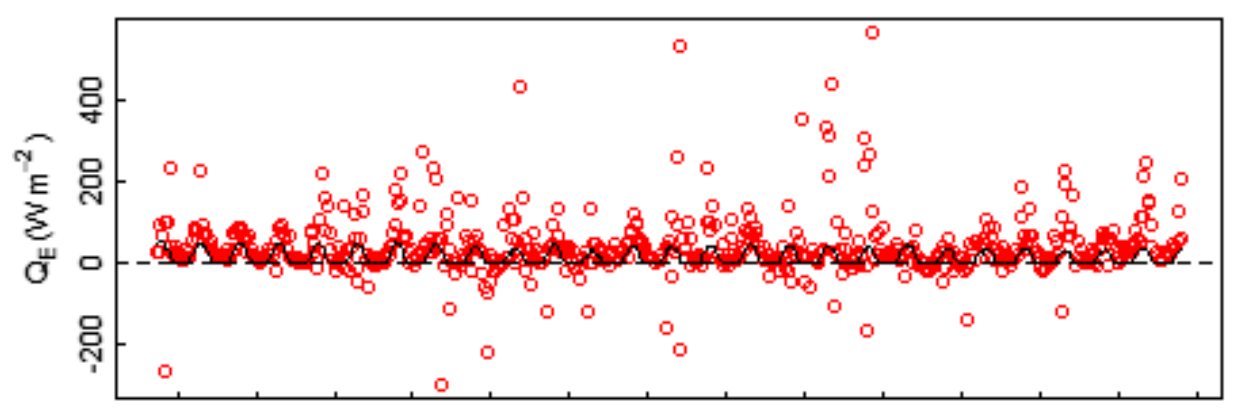

(d)
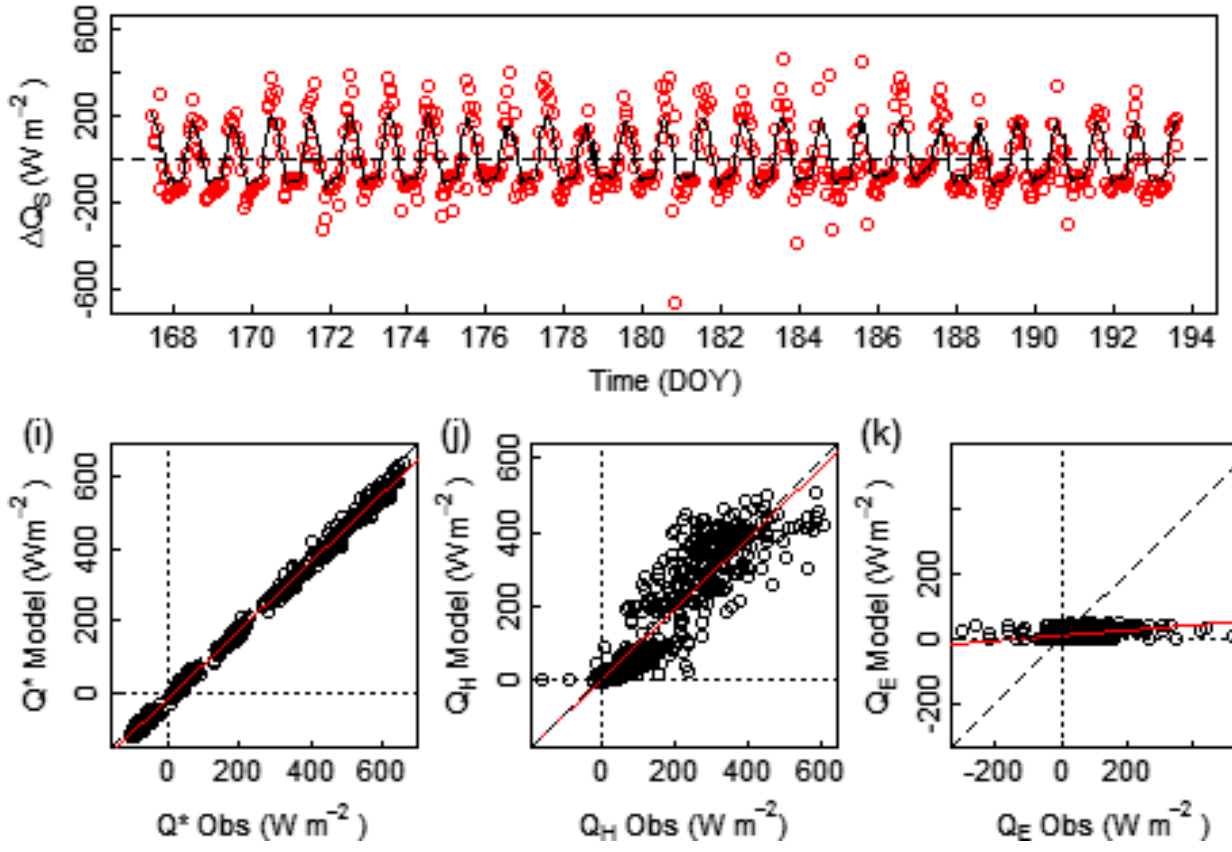

(e)

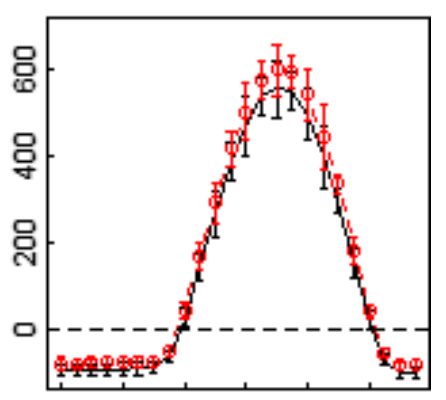

(f)

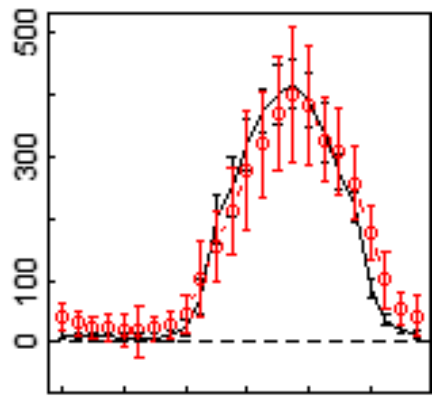

(g)

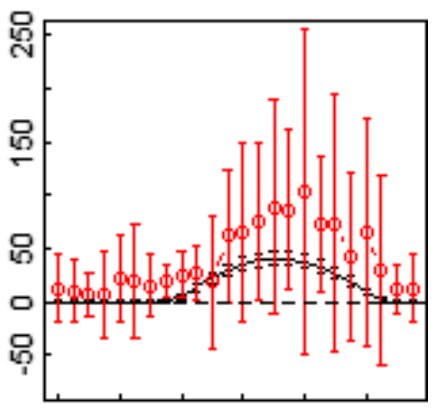

(h)
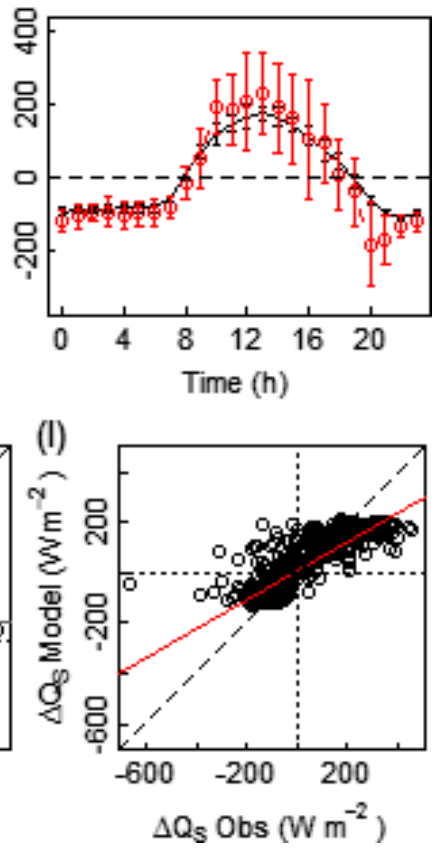

Figure 4. (a)-(d) Time series, (e) - (h) diurnal mean and standard deviation (vertical lines) and (i)-(l) scatter plots of modelled versus observed SEB fluxes for: $Q^{*}(\mathrm{a}, \mathrm{e}, \mathrm{i}), Q_{\mathrm{H}}(\mathrm{b}, \mathrm{f}, \mathrm{j}), Q_{\mathrm{E}}(\mathrm{c}, \mathrm{g}, \mathrm{k})$ and $\Delta Q_{\mathrm{S}}(\mathrm{d}, \mathrm{h}, \mathrm{l})$. This figure is available in colour online at www.interscience.wiley.com/journal/qj 
Table IV. Summary statistics of simulated and observed fluxes for the overall, day, night and transition time periods (see text for details): (a) $Q^{*}$, (b) $Q_{H}$, (c) $Q_{E}$ and (d) $\Delta Q_{s}$.

\begin{tabular}{|c|c|c|c|c|c|}
\hline (a) $Q^{*}$ & Units & All & Day & Night & Transition \\
\hline Number of points & - & 626 & 315 & 78 & 233 \\
\hline Mean (Noah/SLUCM) & $\mathrm{W} \mathrm{m}^{-2}$ & 139.4 & 358.0 & -95.9 & -77.4 \\
\hline Mean (obs) & $\mathrm{W} \mathrm{m}^{-2}$ & 165.1 & 393.5 & -80.4 & -61.4 \\
\hline Standard deviation (Noah/SLUCM) & $\mathrm{W} \mathrm{m}^{-2}$ & 255.7 & 179.6 & 12.3 & 41.1 \\
\hline Standard deviation (obs) & $\mathrm{W} \mathrm{m} \mathrm{m}^{-2}$ & 266.3 & 185.9 & 12.2 & 40.3 \\
\hline Coefficient of determination $\left(\mathrm{R}^{2}\right)$ & - & 0.997 & 0.993 & 0.509 & 0.946 \\
\hline Root mean square error (RMSE) & $\mathrm{W} \mathrm{m}^{-2}$ & 30.8 & 39.3 & 18.1 & 18.7 \\
\hline RMSE systematic $\left(\mathrm{RMSE}_{\mathrm{S}}\right)$ & $\mathrm{W} \mathrm{m}^{-2}$ & 28 & 36.2 & 15.9 & 16 \\
\hline RMSE unsystematic $\left(\mathrm{RMSE}_{U}\right)$ & $\mathrm{W} \mathrm{m}^{-2}$ & 12.9 & 15.5 & 8.6 & 9.6 \\
\hline Mean absolute error (MAE) & $\mathrm{W} \mathrm{m}^{-2}$ & 25.9 & 35.8 & 15.5 & 16.2 \\
\hline Mean bias error (MBE) & $\mathrm{W} \mathrm{m}^{-2}$ & -25.8 & -35.5 & -15.5 & -16.0 \\
\hline $\begin{array}{l}\text { Index of agreement (IOA) } \\
\text { (b) } Q_{H}\end{array}$ & - & 0.997 & 0.988 & 0.597 & 0.949 \\
\hline Number of points & - & 621 & 310 & 78 & 233 \\
\hline Mean (Noah/SLUCM) & $\mathrm{W} \mathrm{m}^{-2}$ & 147.9 & 281.3 & 10.0 & 16.5 \\
\hline Mean (obs) & $\mathrm{W} \mathrm{m}^{-2}$ & 156.4 & 275.5 & 27.0 & 41.4 \\
\hline Standard deviation (Noah/SLUCM) & $\mathrm{W} \mathrm{m}^{-2}$ & 157.2 & 117.5 & 5.9 & 12.6 \\
\hline Standard deviation (obs) & $\mathrm{W} \mathrm{m}^{-2}$ & 147.9 & 119.6 & 19 & 38.4 \\
\hline Coefficient of determination $\left(\mathrm{R}^{2}\right)$ & - & 0.835 & 0.566 & 0.071 & 0.401 \\
\hline Root mean square error (RMSE) & $\mathrm{W} \mathrm{m}^{-2}$ & 64.6 & 83.6 & 24.9 & 40.4 \\
\hline RMSE systematic $\left(\mathrm{RMSE}_{\mathrm{S}}\right)$ & $\mathrm{W} \mathrm{m}^{-2}$ & 9.6 & 31.7 & 24.3 & 39.2 \\
\hline RMSE unsystematic $\left(\mathrm{RMSE}_{\mathrm{U}}\right)$ & $\mathrm{W} \mathrm{m}^{-2}$ & 63.9 & 77.3 & 5.6 & 9.8 \\
\hline Mean absolute error (MAE) & $\mathrm{W} \mathrm{m}^{-2}$ & 47.0 & 66.6 & 19.9 & 30.0 \\
\hline Mean bias error (MBE) & $\mathrm{W} \mathrm{m}^{-2}$ & -8.5 & 5.9 & -17.0 & -24.9 \\
\hline $\begin{array}{l}\text { Index of agreement (IOA) } \\
\text { (c) } Q_{E}\end{array}$ & - & 0.953 & 0.863 & 0.479 & 0.537 \\
\hline Number of points & - & 614 & 303 & 78 & 233 \\
\hline Mean (Noah/SLUCM) & $\mathrm{W} \mathrm{m}^{-2}$ & 14.3 & 28.8 & -0.6 & 0.5 \\
\hline Mean (obs) & $\mathrm{W} \mathrm{m} \mathrm{m}^{-2}$ & 40.2 & 65.2 & 7.8 & 18.5 \\
\hline Standard deviation (Noah/SLUCM) & $\mathrm{W} \mathrm{m} \mathrm{m}^{-2}$ & 16.5 & 11.7 & 1.1 & 1.9 \\
\hline Standard deviation (obs) & $\mathrm{W} \mathrm{m}^{-2}$ & 74 & 90.7 & 30.8 & 42.2 \\
\hline Coefficient of determination $\left(\mathrm{R}^{2}\right)$ & - & 0.133 & 0.028 & 0.006 & 0.008 \\
\hline Root mean square error (RMSE) & $\mathrm{W} \mathrm{m}^{-2}$ & 74.3 & 96.5 & 31.8 & 45.6 \\
\hline RMSE systematic $\left(\mathrm{RMSE}_{\mathrm{S}}\right)$ & $\mathrm{W} \mathrm{m}^{-2}$ & 72.7 & 95.9 & 31.8 & 45.6 \\
\hline RMSE unsystematic $\left(\mathrm{RMSE}_{\mathrm{U}}\right)$ & $\mathrm{W} \mathrm{m} \mathrm{m}^{-2}$ & 15.4 & 11.5 & 1.1 & 1.9 \\
\hline Mean absolute error (MAE) & $\mathrm{W} \mathrm{m}^{-2}$ & 41.5 & 59.4 & 21.2 & 25.1 \\
\hline Mean bias error (MBE) & $\mathrm{W} \mathrm{m}^{-2}$ & -25.9 & -36.5 & -8.4 & -18.0 \\
\hline $\begin{array}{l}\text { Index of agreement (IOA) } \\
\text { (d) } \Delta Q_{S}\end{array}$ & - & 0.344 & 0.32 & 0.236 & 0.275 \\
\hline Number of points & - & 614 & 303 & 78 & 233 \\
\hline Mean (Noah/SLUCM) & $\mathrm{W} \mathrm{m}^{-2}$ & 5.5 & 95.4 & -90.4 & -79.4 \\
\hline Mean (obs) & $\mathrm{W} \mathrm{m}^{-2}$ & -3.8 & 99.9 & -100.2 & -106.3 \\
\hline Standard deviation (Noah/SLUCM) & $\mathrm{W} \mathrm{m}^{-2}$ & 106.1 & 75.8 & 9.5 & 36.4 \\
\hline Standard deviation (obs) & $\mathrm{W} \mathrm{m} \mathrm{m}^{-2}$ & 157.4 & 162.4 & 33.9 & 55.4 \\
\hline Coefficient of determination $\left(\mathrm{R}^{2}\right)$ & - & 0.727 & 0.57 & 0.157 & 0.518 \\
\hline Root mean square error (RMSE) & $\mathrm{W} \mathrm{m}^{-2}$ & 87.3 & 116.1 & 32.7 & 46.9 \\
\hline RMSE systematic $\left(\mathrm{RMSE}_{\mathrm{S}}\right)$ & $\mathrm{W} \mathrm{m}^{-2}$ & 67.5 & 105 & 31.5 & 39.6 \\
\hline RMSE unsystematic $\left(\mathrm{RMSE}_{U}\right)$ & $\mathrm{W} \mathrm{m}^{-2}$ & 55.4 & 49.6 & 8.7 & 25.2 \\
\hline Mean absolute error (MAE) & $\mathrm{W} \mathrm{m}^{-2}$ & 59.3 & 88.6 & 23.9 & 33.0 \\
\hline Mean bias error (MBE) & $\mathrm{W} \mathrm{m}^{-2}$ & 9.2 & -4.5 & 9.9 & 26.8 \\
\hline Index of agreement (IOA) & - & 0.884 & 0.743 & 0.453 & 0.747 \\
\hline
\end{tabular}




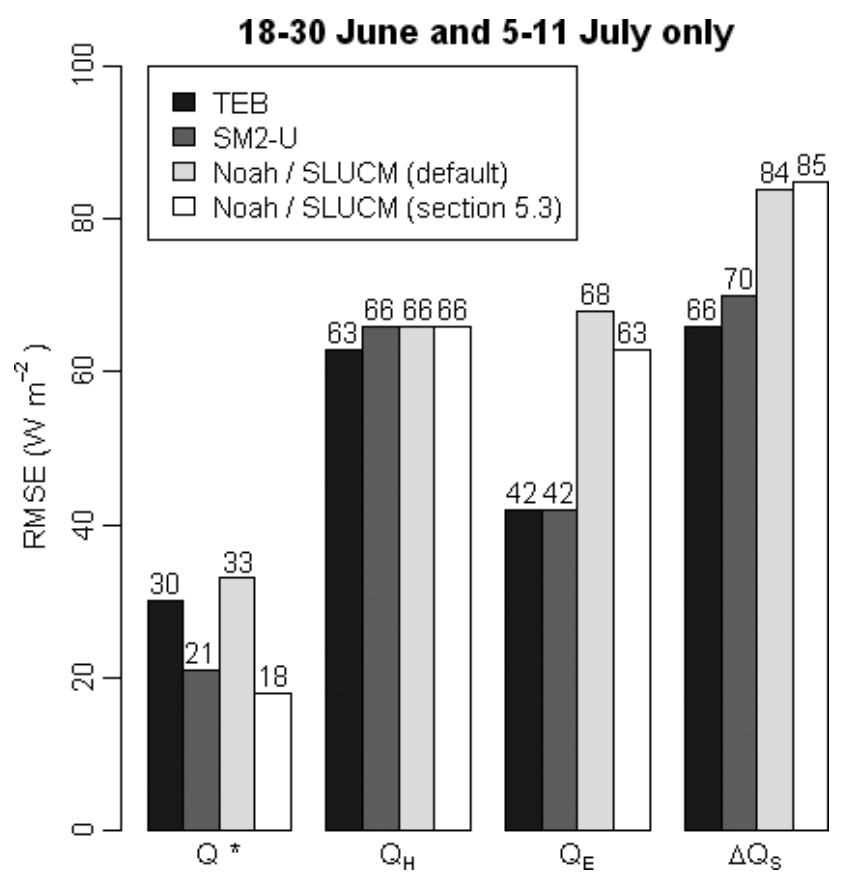

Figure 5. Comparison of RMSE obtained by TEB, SM2-U and Noah / SLUCM using Marseille data for $Q^{*}, Q_{\mathrm{H}}, Q_{\mathrm{E}}$ and $\Delta Q_{\mathrm{S}}$ (see text for details).

values again suggest some fundamental problems in the modelling approach or a bad choice of default parameter values (e.g. vegetation and soil classes). The magnitudes of the MBEs (Table IVc) are similar to those for $Q^{*}$ (section 5 investigates the extent to which both processes are linked). All previously mentioned biases accumulate in the SEB residual $\Delta Q_{S}$ which therefore has the poorest RMSE statistics (Table IVd). As noted in section 4.1, the lack of representation of $S$ and $\Delta Q_{\mathrm{A}}$ in the SLUCM and measurement errors also are incorporated in these results.

To enable a comparison with TEB and SM2-U the RMSE values are recalculated for the same period as the one analysed in the corresponding studies (i.e. 18-30 June and 5-11 July: Lemonsu et al., 2004; Dupont and Mestayer, 2006) (Figure 5). $Q^{*}$ is better modelled by SM2-U, while TEB has the lowest RMSE for $Q_{H}$ and $\Delta Q_{S}$. The performance attained by the Noah/SLUCM is similar to TEB for both $Q^{*}$ and $Q_{H}$, but is considerably poorer than the two other schemes for $Q_{E}$, and consequently $\Delta Q_{S}$. The analysis in section 5 enables determination of whether this bias in the modelling of the turbulent latent heat flux can be solved by a change in the default parameter values or a consequence of a more fundamental problem.

\section{Analysis of model response}

\subsection{Set-up}

Having modified the type of input information needed by the Noah/SLUCM, an assessment of the model response to its updated list of input parameters is required. The systematic and objective procedure introduced in section 2 is applied here to the Table II version of the scheme. The forcing and observation data from Marseille and the section 4 run are used as the reference to provide both default parameters values and RMSE.

After preliminary tests of their influence on the RMSE statistics, 45 out of 68 parameters were selected to be optimized. The remaining 23 were left out of the optimization procedure since they did not influence the model performance (mainly soil- and vegetation-related coefficients involved in the parametrization of processes of little impact in the case of Marseille). Each is given a default value and limits between which it can evolve (Table III). Ranges for each parameter were determined using typical properties of building materials as listed in the ASHRAE tables (ASHRAE, 2005; Anderson, 2009) as well as the Chen and Dudhia (2001) default values for different vegetation and soil classes.

The algorithm is set to initialize 100 samples $(s=100)$, and two sets of MOSCEM runs are performed here:

(1). Using only the RMSE for $Q^{*}$ and $Q_{H}$ as objective functions, the key parameters in modelling $Q^{*}$ are identified while providing some insight on the processes transferring the energy towards $Q_{\mathrm{H}}$. Discarding the RMSE for $Q_{\mathrm{E}}$ from the procedure, this first set of runs focuses on the two largest fluxes of the urban energy balance. It also enables a graphical representation of trade-offs illustrating many of the concepts introduced in section 2 .

(2). Adding the RMSE for $Q_{\mathrm{E}}$ as a third objective forces MOSCEM to search for the best overall compromise (in terms of RMSE).

\subsection{Optimization with regard to $Q^{*}$ and $Q_{\mathrm{H}}$}

Results from the multi-objective runs optimizing the RMSE for $Q^{*}$ and $Q_{\mathrm{H}}$ are presented in scatter plots (Figure 6) also known as 'objective spaces', which clearly illustrate the two distinct behaviours discussed in section 2:

- For some parameters an optimum value emerges: the 100 solutions are clustered in a very compact area of the objective space, and at least one of the RMSE is improved from the performance obtained with the default run of section $4\left(\triangle \mathrm{RMSE} \leq 0 \mathrm{~W} \mathrm{~m}^{-2}\right)$ (e.g. Figure 6, panel 1: $Z_{\mathrm{R}}$ ).

- For the remaining parameters only a Pareto front of solution is identified: their optimization results in some 'trade-offs' in the modelling of the two fluxes (e.g. Figure 6, panel 6: $\alpha_{\text {roof }}$ )

Additionally, results from a set of control single-objective runs (using only one of the RMSE as objective) are reported on the plots (solid lines) to underline the ability of MOSCEM to cover the entire range of trade-offs and reach the same performances as when optimization is done for only one flux. Interestingly, in some cases the multi-objective runs outperform the single-objective ones suggesting that the algorithm is more efficient in its multi-objective mode.

The extent of RMSE improvement relates to the sensitivity of the model to a specific parameter. The 20 parameters with largest impact on the default RMSE for $Q^{*}$ (Table Va) and $Q_{\mathrm{H}}($ Table $\mathrm{Vb})$ are ranked, and corresponding changes in RMSE for the other two fluxes directly simulated by the model are reported as an indication of possible tradeoffs. To further illustrate the importance of such trade-offs the 20 parameters leading to a Pareto front of solution are presented (Table VI). The ranking in terms of biggest improvement in RMSE of one flux $\left(Q^{*}\right.$ in Table VIa, $Q_{H}$ in Table VIb) can be obtained from a change of value along the front (i.e. by moving from the value giving the lowest 

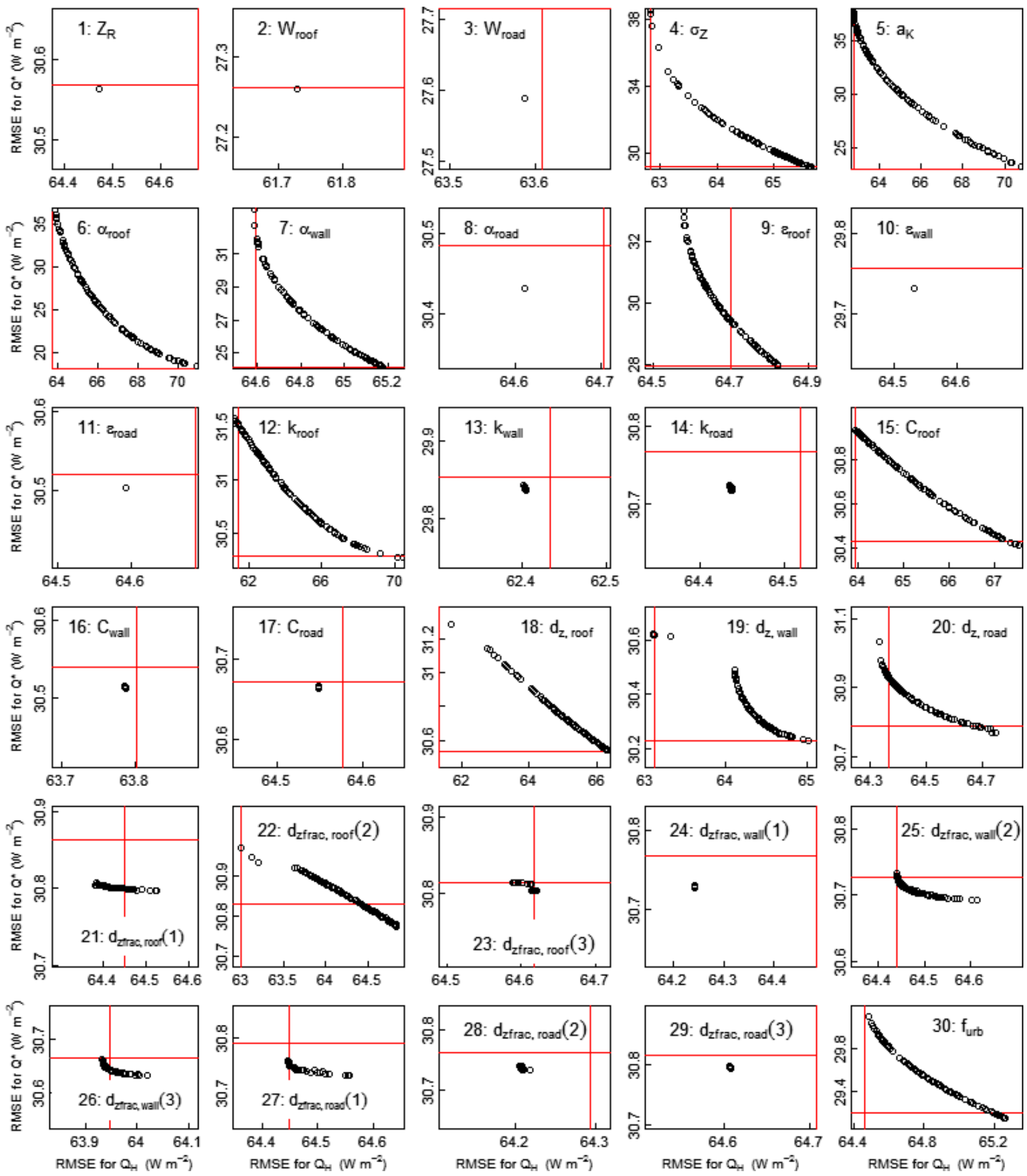

Figure 6. RMSE for the 100 samples identified as optimum by MOSCEM when optimized for both the RMSE for $Q^{*}$ and $Q_{H}$. The results from control single-objective runs are also plotted (solid lines). Parameters 1 to 29 (SLUCM-related) and the urban fraction ( $\left.f_{\text {urb }}\right)$ are shown. See Table III for definitions. This figure is available in colour online at www.interscience.wiley.com/journal/qj

RMSE to the one giving the highest). The impact of the same value change on the other fluxes is also listed to show the trade-offs (i.e. when $\triangle \mathrm{RMSE}>0 \mathrm{~W} \mathrm{~m}^{-2}$ ). Among the parameters selected to be optimized, two categories can be distinguished: parameters defining the urban morphology, radiative properties, heat capacities, conductivities or depth of materials for instance can to a certain extent be assigned objective values based on observation at a given site. They represent the first category of inputs which can be related to a measurable physical quantity. On the other hand, parameters such as $a_{\mathrm{K}}$ or $C_{\mathrm{ZIL}}$ must be seen as 'tunable' quantities since they arise from empirical models which are by nature only a simplification of physical phenomena too complex to be explicitly resolved (e.g. momentum, heat and moisture exchange by turbulent transport). In that sense they do not relate to any objectively measurable quantity and can only be determined with regard to a given experiment (e.g. Kanda et al. (2007) found $a_{\mathrm{K}}$ varied (1.24-1.41) depending on dataset in their study). Although not an input, coefficients $\alpha_{\mathrm{m}}$ and $\beta_{\mathrm{m}}$ from MacDonald et al. (1998) are in the same 
Table V. Sensitivity of (a) the net all-wave radiation $\left(Q^{*}\right)$ and $(b)$ the turbulent sensible heat flux $\left(Q_{\mathrm{H}}\right)$ simulated by Noah / SLUCM. The 20 input parameters with the largest influence on RMSE performance, ranked based on best improvement made by a change in their default value $\left(\triangle \mathrm{RMSE} \leq 0 \mathrm{~W} \mathrm{~m}^{-2}\right)$ are shown. Impact on the RMSE of the other two modelled fluxes is also given as an indication of trade-offs.

\begin{tabular}{|c|c|c|c|c|c|c|}
\hline (a) & Parameter & Default & Optimum & Gain in $Q^{*}(\Delta \mathrm{RMSE})$ & Impact on $Q_{\mathrm{H}}(\Delta \mathrm{RMSE})$ & Impact on $Q_{E}(\Delta \mathrm{RMSE})$ \\
\hline 1 & $\alpha_{\text {roof }}$ & 0.22 & 0.135 & -12.39 & 6.35 & 0 \\
\hline 2 & $a_{\mathrm{K}}$ & 1.29 & 0.529 & -7.60 & 6.17 & 0 \\
\hline 3 & $\alpha_{\text {wall }}$ & 0.2 & 0.052 & -6.62 & 0.56 & 0 \\
\hline 4 & $\alpha_{\mathrm{veg}}$ & 0.23 & 0.102 & -6.36 & 1.17 & -0.74 \\
\hline 5 & $W_{\text {roof }}$ & 21.2 & 11.2 & -3.54 & -2.89 & 0 \\
\hline 6 & $W_{\text {road }}$ & 9.6 & 15.6 & -3.21 & -1.03 & 0 \\
\hline 7 & $\varepsilon_{\text {roof }}$ & 0.9 & 0.851 & -2.81 & 0.20 & 0 \\
\hline 8 & $f_{\text {urb }}$ & 0.864 & 0.764 & -1.66 & 0.64 & -3.73 \\
\hline 9 & $\sigma_{Z}$ & 9 & 14.946 & -1.62 & 1.06 & 0 \\
\hline 10 & $\varepsilon_{\text {wall }}$ & 0.9 & 0.98 & -1.07 & -0.09 & 0 \\
\hline 11 & $k_{\text {wall }}$ & 0.55 & 2.299 & -0.97 & -2.22 & 0 \\
\hline 12 & $\varepsilon_{\mathrm{veg}}$ & 0.93 & 0.880 & -0.61 & 0.04 & -0.08 \\
\hline 13 & $d_{z, \text { wall }}$ & 0.26 & 0.894 & -0.57 & 0.41 & 0 \\
\hline 14 & $k_{\text {roof }}$ & 0.9 & 0.363 & -0.53 & 5.81 & 0 \\
\hline 15 & $C_{\text {roof }}$ & 1769000 & 604674 & -0.39 & 2.91 & 0 \\
\hline 16 & $\alpha_{\text {road }}$ & 0.08 & 0.05 & -0.37 & -0.01 & 0 \\
\hline 17 & $\varepsilon_{\text {road }}$ & 0.94 & 0.98 & -0.30 & -0.03 & 0 \\
\hline 18 & $C_{\text {wall }}$ & 1676000 & 2299510 & -0.29 & -0.83 & 0 \\
\hline 19 & $d_{z, \text { roof }}$ & 0.32 & 0.496 & -0.26 & 1.69 & 0 \\
\hline 20 & $Z_{\mathrm{R}}$ & 15.6 & 18.599 & -0.24 & -0.15 & 0 \\
\hline (b) & & & & Gain in $Q_{H}(\Delta \mathrm{RMSE})$ & Impact on $Q^{*}(\Delta \mathrm{RMSE})$ & \\
\hline 1 & $k_{\text {roof }}$ & 0.9 & 1.495 & -3.38 & 0.78 & 0 \\
\hline 2 & $d_{z, \text { roof }}$ & 0.32 & 0.16 & -2.93 & 0.49 & 0 \\
\hline 3 & $W_{\text {roof }}$ & 21.2 & 11.2 & -2.89 & -3.54 & 0 \\
\hline 4 & $k_{\text {wall }}$ & 0.55 & 2.3 & -2.22 & -0.96 & 0 \\
\hline 5 & $a_{\mathrm{K}}$ & 1.29 & 1.999 & -1.90 & 7.12 & 0 \\
\hline 6 & $\sigma_{Z}$ & 9 & 3.168 & -1.80 & 7.55 & 0 \\
\hline 7 & $d_{z \text { frac,roof }}(2)$ & 0.468 & 0.228 & -1.62 & 0.17 & 0 \\
\hline 8 & $d_{z, \text { wall }}$ & 0.26 & 0.1 & -1.53 & -0.18 & 0 \\
\hline 9 & $R_{\mathrm{cmin}}$ & 170 & 40.234 & -1.22 & 0 & -2.25 \\
\hline 10 & $W_{\text {road }}$ & 9.6 & 15.6 & -1.03 & -3.21 & 0 \\
\hline 11 & $C_{\mathrm{ZIL}}$ & 0.1 & 0.999 & -0.91 & 0 & 0.70 \\
\hline 12 & $C_{\text {wall }}$ & 1676000 & 2299910 & -0.84 & -0.29 & 0 \\
\hline 13 & $\alpha_{\text {roof }}$ & 0.22 & 0.248 & -0.79 & 5.95 & 0 \\
\hline 14 & $d_{z \text { frac,wall }}(3)$ & 0.57 & 0.146 & -0.69 & -0.14 & 0 \\
\hline 15 & $C_{\text {roof }}$ & 1769000 & 2283860 & -0.69 & 0.13 & 0 \\
\hline 16 & $\alpha_{\mathrm{veg}}$ & 0.23 & 0.298 & -0.47 & 3.70 & 0.47 \\
\hline 17 & LAI & 3 & 4.995 & -0.46 & 0 & -0.76 \\
\hline 18 & $d_{z \text { frac,road }}(2)$ & 0.16 & 0.1 & -0.42 & -0.06 & 0 \\
\hline 19 & $d_{z \text { frac,wall }}(1)$ & 0.038 & 0.1 & -0.38 & -0.07 & 0 \\
\hline 20 & $d_{z, \text { road }}$ & 1.24 & 0.663 & -0.29 & 0.23 & 0 \\
\hline
\end{tabular}

category (Table II, Eqs 17, 18). Other examples include soiland vegetation-related coefficients such as the minimum stomatal resistance $\left(R_{\mathrm{cmin}}\right)$ or the radiation stress parameter $\left(R_{\mathrm{gl}}\right)$. As far as this second category is concerned, departures between default and MOSCEM-selected optimum values can be (partly) attributed to conditions differing from either the theoretical framework in which they were developed or the dataset used to determine their initial estimates. For the first category, any departure from the default measured values needs to be interpreted as an attempt of MOSCEM to compensate for model deficiencies and for uncertainties in estimating parameters.

Table V highlights a strong sensitivity of the model to all roof-related parameters. This relates to the direct impact roof surfaces have on the simulation of $Q^{*}$ and $Q_{H}$ (no canyon interference) and the dominant role they play in a dense city with narrow streets such as Marseille (plan area fraction $\lambda_{p}=0.69$, frontal area index $\left.\lambda_{F}=0.5\right)$. The values identified as optimum, based on the RMSE for $Q^{*}$, can be interpreted as an attempt to provide more radiative 
Table VI. Trade-off effects in the modelling of $Q^{*}$ and $Q_{H}$. Parameters are ranked in terms of the biggest improvement in

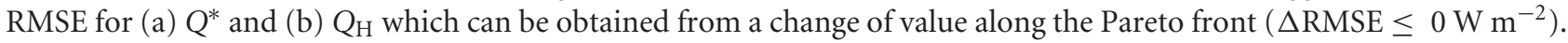

The corresponding impact on the RMSE for the other fluxes is reported as a measure of the trade-off effects.

\begin{tabular}{|c|c|c|c|c|c|}
\hline (a) & Parameter & Change in value & Gain in $Q^{*}(\Delta \mathrm{RMSE})$ & Impact on $Q_{H}(\Delta$ RMSE) & Impact on $Q_{E}(\Delta \mathrm{RMSE})$ \\
\hline 1 & $\alpha_{\text {roof }}$ & 0.248 to 0.135 & -18.34 & 7.14 & 0 \\
\hline 2 & $a_{\mathrm{K}}$ & 1.999 to 0.529 & -14.72 & 8.07 & 0 \\
\hline 3 & $\alpha_{\mathrm{veg}}$ & 0.298 to 0.102 & -10.05 & 1.65 & -1.21 \\
\hline 4 & $\alpha_{\text {wall }}$ & 0.255 to 0.052 & -9.43 & 0.59 & 0 \\
\hline 5 & $\sigma_{Z}$ & 3.168 to 14.946 & -9.36 & 2.86 & 0 \\
\hline 6 & $\varepsilon_{\text {roof }}$ & 0.938 to 0.851 & -4.95 & 0.24 & 0 \\
\hline 7 & $k_{\text {roof }}$ & 1.495 to 0.363 & -1.31 & 9.20 & 0 \\
\hline 8 & $\varepsilon_{\mathrm{veg}}$ & 0.970 to 0.880 & -1.1 & 0.07 & -0.14 \\
\hline 9 & $f_{\text {urb }}$ & 0.822 to 0.764 & -0.95 & 0.78 & -1.75 \\
\hline 10 & $d_{z \text { roof }}$ & 0.16 to 0.496 & -0.75 & 4.62 & 0 \\
\hline 11 & $C_{\text {roof }}$ & 2283860 to 604674 & -0.52 & 3.59 & 0 \\
\hline 12 & $d_{z, \text { wall }}$ & 0.1 to 0.894 & -0.39 & 1.93 & 0 \\
\hline 13 & $d_{z, \text { road }}$ & 0.663 to 1.942 & -0.26 & 0.41 & 0 \\
\hline 14 & $d_{z \text { frac,roof }}(2)$ & 0.228 to 0.490 & -0.19 & 1.85 & 0 \\
\hline 15 & $d_{z \text { frac,wall }}(2)$ & 0.220 to 0.297 & -0.04 & 0.18 & 0 \\
\hline 16 & $d_{z \text { frac,wall }}(3)$ & 0.147 to 0.211 & -0.03 & 0.09 & 0 \\
\hline 17 & $d_{z \text { frac,road }}(1)$ & 0.068 to 0.097 & -0.03 & 0.11 & 0 \\
\hline 18 & $d_{z \text { frac,roof }}(3)$ & 0.100 to 0.378 & -0.01 & 0.03 & 0 \\
\hline 19 & $d_{z \text { frac,roof }}(1)$ & 0.099 to 0.078 & -0.01 & 0.14 & 0 \\
\hline 20 & $d_{z \text { frac,road }}(2)$ & 0.1 to 0.101 & -0.01 & 0.01 & 0 \\
\hline
\end{tabular}

\begin{tabular}{|c|c|c|c|c|c|}
\hline (b) & & & Gain in $Q_{\mathrm{H}}(\Delta \mathrm{RMSE})$ & Impact on $Q^{*}(\Delta \mathrm{RMSE})$ & \\
\hline 1 & $k_{\text {roof }}$ & 0.363 to 1.495 & -9.20 & 1.31 & 0 \\
\hline 2 & $a_{\mathrm{K}}$ & 0.529 to 1.999 & -8.07 & 14.72 & 0 \\
\hline 3 & $\alpha_{\text {roof }}$ & 0.135 to 0.248 & -7.14 & 18.34 & 0 \\
\hline 4 & $d_{z \text { roof }}$ & 0.496 to 0.16 & -4.62 & 0.75 & 0 \\
\hline 5 & $C_{\text {roof }}$ & 604674 to 2283860 & -3.59 & 0.52 & 0 \\
\hline 6 & $\sigma_{Z}$ & 14.946 to 3.168 & -2.86 & 9.36 & 0 \\
\hline 7 & $d_{z, \text { wall }}$ & 0.894 to 0.1 & -1.93 & 0.39 & 0 \\
\hline 8 & $d_{z \text { frac,roof }}(2)$ & 0.49 to 0.228 & -1.85 & 0.19 & 0 \\
\hline 9 & $\alpha_{\mathrm{veg}}$ & 0.102 to 0.298 & -1.65 & 10.05 & 1.21 \\
\hline 10 & $f_{\mathrm{urb}}$ & 0.764 to 0.822 & -0.78 & 0.95 & 1.75 \\
\hline 11 & $\alpha_{\text {wall }}$ & 0.052 to 0.255 & -0.59 & 9.43 & 0 \\
\hline 12 & $d_{z, \text { road }}$ & 1.942 to 0.663 & -0.41 & 0.26 & 0 \\
\hline 13 & $\varepsilon_{\text {roof }}$ & 0.851 to 0.934 & -0.24 & 4.96 & 0 \\
\hline 14 & $d_{z \text { frac,wall }}(2)$ & 0.297 to 0.22 & -0.18 & 0.04 & 0 \\
\hline 15 & $d_{z \text { frac,roof }}(1)$ & 0.078 to 0.1 & -0.14 & 0.01 & 0 \\
\hline 16 & $d_{z \text { frac,road }}(1)$ & 0.098 to 0.0676 & -0.11 & 0.03 & 0 \\
\hline 17 & $d_{z \text { frac,wall }}(3)$ & 0.223 to 0.147 & -0.09 & 0.03 & 0 \\
\hline 18 & $\varepsilon_{\mathrm{veg}}$ & 0.880 to 0.969 & -0.07 & 1.1 & 0.14 \\
\hline 19 & $d_{z \text { frac,roof }}(3)$ & 0.378 to 0.1 & -0.03 & 0.01 & 0 \\
\hline 20 & $d_{z \text { frac,road }}(2)$ & 0.102 to 0.1 & -0.01 & 0.01 & 0 \\
\hline
\end{tabular}

energy (reduction of $\alpha_{\text {roof }}, \varepsilon_{\text {roof }}$ ) while reducing heat storage (reduction of $C_{\text {roof }}, k_{\text {roof }}$ ), thus increasing the available energy for the turbulent fluxes. This tends to decrease both the day and night-time biases for the default case (Figure 4, Table IVa) since a larger proportion of the incoming solar energy would be made available during the day when it can be dissipated via turbulent processes hence limiting the long-wave emissions. It would also reduce the large negative values of night-time $Q^{*}$ by keeping the roof temperature lower when turbulent activity is typically weak and energy is mostly lost as $L \uparrow$. Yet it also triggers an increase in the RMSE of $Q_{\mathrm{H}}$ (i.e. a trade-off); with a limited storage capacity, solar radiation warms roof surfaces with almost no time lag, hence strengthening the daytime temperature gradient between the roof and the air at forcing level. As a result, exchanges of heat via turbulent processes are enhanced and the model reaches a state where it overestimates the sensible heat fluxes. The observed peak turbulent sensible heat fluxes may also be underestimated (Foken, 2008b). This suggests roof characteristics must be determined with great care due to their large impact on the RMSE of $Q^{*}$ and $Q_{H}$ and potential trade-offs.

The optimization of canyon parameters (walls, road) is the source of fewer trade-off effects than roof-related ones, and 

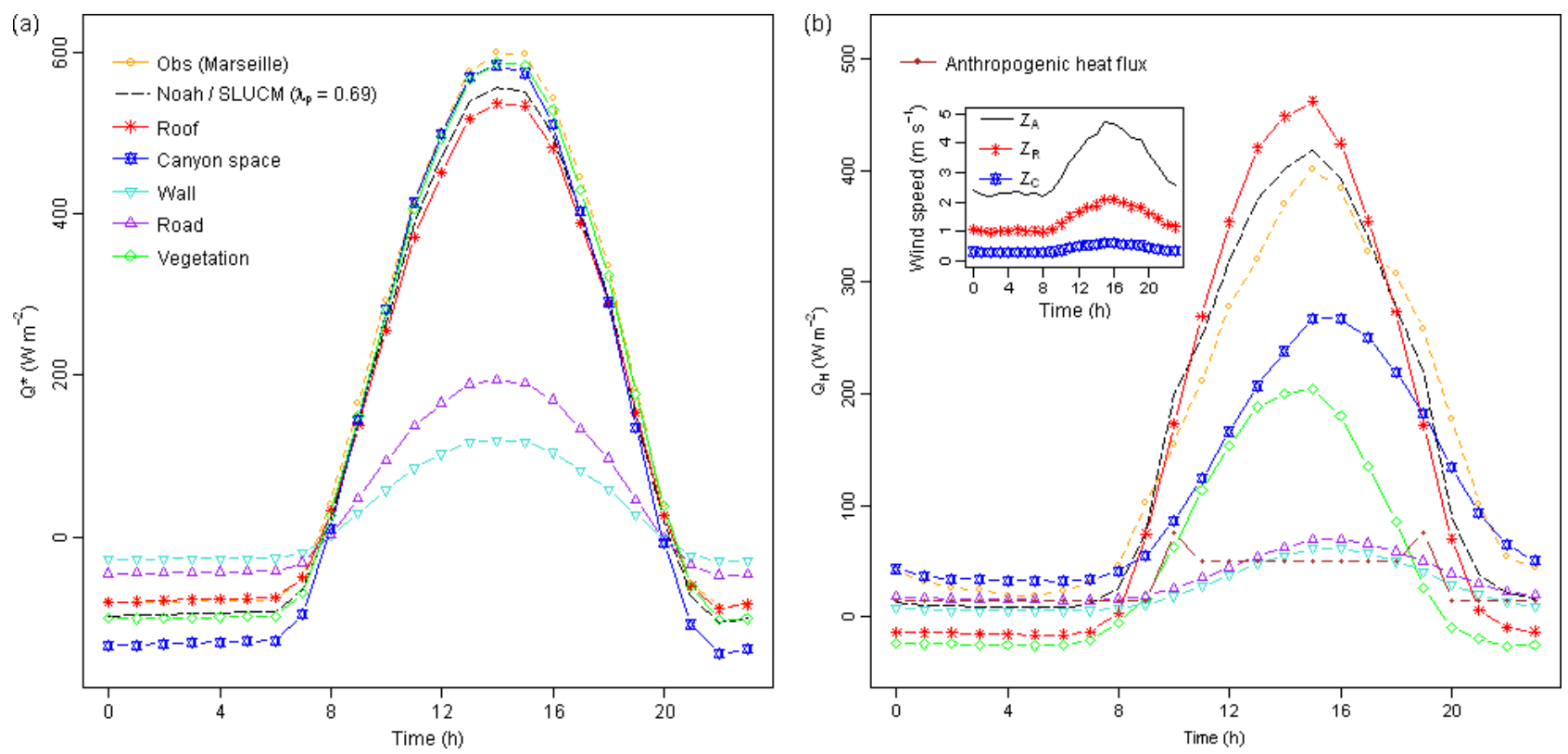

Figure 7. Based on Marseille forcing and observations the contribution of each surface represented in Noah/SLUCM for (a) $Q^{*}$, and (b) $Q_{\mathrm{H}}$. Inset to (b): diurnal mean wind speeds at forcing level $\left(Z_{\mathrm{A}}\right)$, roof level $\left(Z_{\mathrm{R}}\right)$ and inside canyon $\left(Z_{\mathrm{C}}\right)$. The anthropogenic heat flux $Q_{\mathrm{F}}(\mathrm{Grimmond}$ et al., 2004$)$ is plotted in (b). This figure is available in colour online at www.interscience.wiley.com/journal/qj

in many cases an optimum state is identified (e.g. for $\alpha_{\text {road }}$, $\varepsilon_{\text {road }}, \varepsilon_{\text {wall }}, k_{\text {road }}, k_{\text {wall }}, C_{\text {road }}$ or $\left.C_{\text {wall }}\right)$. As argued by Harman and Belcher (2006) this shows heterogeneities between the energy balance of the roof and canyon, and underlines the importance of an accurate estimate of the relative space they occupy. Parameters characterising road properties do not show significant impact on any of the RMSE values suggesting that, if left with the choice, more effort should be put to determining appropriate values for roof or wall characteristics than road ones (e.g. when refining urban land-cover data for a particular site). Among the different properties considered, albedo values are most critical for $Q^{*}$ while conductivities as well as the roof thickness particularly influence $Q_{H}$. These conclusions are valid for particularly dense cities, like the one investigated $\left(\lambda_{\mathrm{p}}=0.69, \lambda_{\mathrm{F}}=0.5\right)$ on the upper end of the range indicated by Grimmond and Oke (1999).

$W_{\text {road }}$ and $W_{\text {roof }}$ are ranked highly but do not trigger any trade-offs. This underlines the key role they play in normalizing all morphological parameters (Table II, Eqs $12-15,19)$ and therefore in defining the relative importance of roof and canyon exchange processes. The impact on the mean diurnal fluxes of the components involved in modelling $Q^{*}$ (Figure $7(\mathrm{a})$ ) and $Q_{\mathrm{H}}$ (Figure $7(\mathrm{~b})$ ) at the forcing level, with the walls and road contributions combined into the canyon component, can be analysed. This comparison prior to their weighting helps to explain the clear tendency towards an increase of the canyon space which results from the optimum values selected by MOSCEM (decrease of $W_{\text {roof }}$, increase of $W_{\text {road }}$ ). Assigning more weight to the canyon space allows more trapping of the incoming radiation (Figure $7(\mathrm{a})$ ) while minimizing the relative importance of turbulent exchange above roof surfaces (Figure $7(\mathrm{~b})$ ) which can be attributed to higher wind speed values at roof level than inside the canyon (inset Figure $7(\mathrm{~b}))$. However, as both $W_{\text {roof }}$ and $W_{\text {road }}$ are involved in the parametrization of the roughness length above the canyon and roof surfaces (Table II, Eqs 16-20) the impact on $Q_{H}$ is not limited to the relative weight each surface is assigned.

There are two main ways canyon structure impacts modelling of $Q_{\mathrm{H}}$ (Figure 8). The relative space occupied by roof surfaces can be reduced (by a direct reduction of the roof width or a wider road) (Figure 8(a) and (d)). Such a change limits the weight assigned to the roof contribution $\left(F_{\text {roof }}\left(=\lambda_{\mathrm{P}}\right)<0.6\right)$, but this enhances its magnitude via an increased roughness (Table II, Eqs 19, 20). The resulting impact on modelled $Q_{H}$ at the forcing level is therefore limited. The opposite case is an increased roof contribution (Figure $8(\mathrm{~b})-(\mathrm{c})$ ) (roof is widened or road narrowed). Although the roof roughness is now reduced, its increased weight compensates, keeping the overall impact on $Q_{\mathrm{H}}$ low. Note that in the most extreme case (Figure 8(c), $\left.F_{\text {roof }}=0.85\right)$ the roof contribution is almost sufficient to represent the overall $Q_{H}$ value (skimming flow regime).

$W_{\text {roof }}$ and $W_{\text {road }}$ form the basis of the homogenized input list (section 3) and can be estimated with good confidence from GIS data. The high responsiveness of the model to their values is therefore acceptable. Yet the extreme values selected during the optimization procedure $\left(W_{\text {roof }}=11.2 \mathrm{~m}\right.$ and $W_{\text {road }}=15.6 \mathrm{~m}$ ) highlight some deficiencies of the scheme with regard to the modelling of $Q^{*}$ and $Q_{\mathrm{H}}$ (first category of inputs).

The scheme is far less sensitive to the $\sigma_{Z}$ parameter than it was to the previously required value of $Z_{0 \mathrm{R}}$ (Loridan et al., 2009). As noted, its estimation is relatively straightforward and therefore the sensitivity to its value does not appear excessive. The value selected by MOSCEM when optimizing for $Q_{\mathrm{H}}$ did not reach the lower limit indicating that reducing $\sigma_{Z}$ to a value of $3.16 \mathrm{~m}$ was sufficient to reach an optimum RMSE in the case of Marseille. The size is also physically reasonable as it is the order of one storey. This again represents a compensation for other shortcomings of the scheme (first category of inputs) but suggests that the model responds effectively to a change in $\sigma_{Z}$.

The sensitivity of the scheme to $a_{\mathrm{K}}$, and the significant trade-offs associated with any change demonstrates the 
importance of adequate characterization of the ratio of roughness length for heat and momentum in urban areas. It also confirms the results of the sensitivity analysis performed with the SUMM model using the same parametrization (Kawai et al., 2007, 2009). Previously introduced in this section as a 'tunable' quantity (second category of inputs), the choice of an appropriate value for the Marseille dataset would depend on the relative importance given to each of the two optimized fluxes: any reduction of $a_{\mathrm{K}}$ greatly improves the modelling of $Q^{*}$ but has a negative impact on $Q_{\mathrm{H}}$ (Figure 6, panel 5, Table VIa); the opposite is true for any increase of $a_{\mathrm{K}}$ (Table VIb).

To assess the extent to which this second category of 'tunable' parameters can impact the performance of the scheme (in terms of the RMSE for $Q^{*}$ and $Q_{H}$ ), a multiparameter run is performed optimizing the main empirical coefficients involved in the turbulence parametrization equations $\left(a_{\mathrm{K}}, C_{\mathrm{ZIL}}, \alpha_{\mathrm{m}}\right.$ and $\left.\beta_{\mathrm{m}}\right)$. This allows all possible 'tuning' combinations to be accounted for through multiparameter optimization. Figure 9 shows the objective plots of the 100 samples used in this multi-parameter run, along with the corresponding combinations of values selected by MOSCEM (inset). The minimum and maximum values that are the basis for each normalization are given in Figure 9. The combinations which perform best (for $Q^{*}$ and $Q_{\mathrm{H}}$ respectively) lie in different areas of the ranges. This suggests, once again, that no optimum values exist for the modelling of the two fluxes (ideally all samples (grey lines) would follow the same unique line indicating the values to be assigned to each coefficient). For $Q^{*}$ the combined impact of the four parameters results in a minimum RMSE of $16 \mathrm{~W} \mathrm{~m}^{-2}$. However, a careful inspection of the combined values suggest $\alpha_{\mathrm{m}}$ and $a_{\mathrm{K}}$ reach their minimum which shows the danger of this kind of model optimization: when trying to compensate for other model deficiencies (here a negative bias in $\left.Q^{*}\right)$, MOSCEM can yield physically unrealistic values (e.g. a higher roughness length for heat than momentum if $a_{\mathrm{K}}=0.1$ and the roughness Reynolds number is very small). It should be remembered that MOSCEM does not consider the physical meaning of a parameter, so analysis of the role of each parameter in the processes parametrized is required before changing their default values. In this particular case, tuning the coefficients to minimize the RMSE for $Q^{*}$ is not advisable as it would result in considerable deterioration of the modelling of the turbulent processes. For $Q_{\mathrm{H}}$, the best combination leads to a minimum RMSE of $62 \mathrm{~W} \mathrm{~m}^{-2}$, with all four coefficients being assigned values consistent with the parametrization they impact $\left(C_{\mathrm{ZIL}}=0.92, \alpha_{\mathrm{m}}=5.7\right.$, $\beta_{\mathrm{m}}=1.83$ and $\left.a_{\mathrm{K}}=1.9\right)$. Consequently it can be argued that for this site a physically plausible optimum setting to model $Q_{\mathrm{H}}$ has been identified within the parameter space. This highlights the added complexity of a model response analysis using MOSCEM in a multi-parameter mode: parameter value changes tend to compensate for each other leaving any detailed analysis of model sensitivity to a particular input almost impossible.

The inability of all SLUCM-related parameters to influence the RMSE for $Q_{\mathrm{E}}$ shows some limitation to modelling $Q_{\mathrm{E}}$ within the urban tile. As no water reservoir is included in the SLUCM, urban evaporation is limited to rain episodes. In addition no transfer of energy from $Q^{*}$ to $Q_{\mathrm{E}}$ is directly represented by Noah/SLUCM: all incoming radiative energy retained in the urban tile is either dissipated as sensible heat or stored in the urban fabric; and $Q_{E}$ is entirely dealt with by Noah. Section 5.3, where the RMSE for $Q_{\mathrm{E}}$ is included as an objective function in the optimization procedure, is designed to identify the key parameters to which its modelling is sensitive.

\subsection{Optimization with regards to $Q^{*}, Q_{H}$ and $Q_{E}$}

Results from sensitivity rankings for modelling $Q^{*}$ and $Q_{\mathrm{H}}$ do not provide any additional information to what is presented in Table V and are therefore not shown. Table VII has the 16 parameters, with some influence on $Q_{E}$, ranked based on their impact on the RMSE for $\mathrm{Q}_{\mathrm{E}}$. After the urban fraction $\left(f_{\text {urb }}\right)$, the parameters the scheme is the most sensitive to are stomatal resistance $\left(R_{\mathrm{cmin}}\right)$, followed by Leaf Area Index (LAI). In Noah, both these parameters are involved in the parametrization of the canopy resistance which is required in canopy evapotranspiration. Both the decrease of $R_{\mathrm{cmin}}$ and increase of LAI suggested by MOSCEM lead to a reduction of the canopy resistance (Eq. 16 from Chen and Dudhia, 2001), and therefore an enhancement of the transpiration from the vegetation. The other parameters effectively acting on $Q_{\mathrm{E}}$ are the soil characteristics $\left(\Theta_{\mathrm{ref}}\right.$, $\left.\Theta_{\text {dry }}, \Theta_{w}, \Theta_{s}\right)$ which determine the direct evaporation from the ground, and are used to determine plant transpiration through available soil moisture in root zone and water stress response function for the canopy resistance. In particular, the reduction of the reference soil moisture content $\Theta_{\text {ref }}$ (field capacity) arising from the optimization is directly linked to an increase in the direct evaporation from the soil. However, since it is the green vegetation fraction $f_{\mathrm{v}}$ which partitions the total evaporation between soil direct and canopy evaporation, the increase in its value resulting from the optimization indicates that canopy evaporation is the dominant factor. The choice of a vegetation class with a low $R_{\text {cmin }}$, combined with high LAI and $f_{\mathrm{v}}$ is therefore recommended for urban applications. Only eight parameters lead to some trade-offs and the corresponding ranking is presented in Table VIII.

For all parameters characterizing evaporative properties of soil and vegetation $\left(R_{\mathrm{cmin}}, \mathrm{LAI}, R_{\mathrm{gl}}, h_{\mathrm{s}}, f_{\mathrm{v}}, \Theta_{\mathrm{ref}}, \Theta_{\mathrm{dry}}, \Theta_{\mathrm{w}}\right.$, $\left.\Theta_{S}\right)$, the improvement in RMSE for $Q_{E}$ provided by their optimization is associated with an improvement in $Q_{H}$. In the vegetated tile, $Q^{*}$ is shared between $Q_{H}$ and $Q_{E}$. Any enhancement of $Q_{E}$ which does not modify the radiative balance directly leads to a decrease in $Q_{\mathrm{H}}$. Given the daytime positive bias of $Q_{H}$ in the default simulation, this translates into a decrease of its RMSE. This is particularly interesting since it represents the way in which energy can be transferred indirectly from one scheme to another in a tile approach model such as Noah/SLUCM: with its canyon structure and building materials allowing high energy storage, the SLUCM has the ability to retain incoming radiation. The poor representation of evaporative processes in the absence of a water reservoir inside the urban tile only permits the dissipation of energy via turbulent sensible heat or its storage. To compensate for this underestimation of the urban contribution to $Q_{E}$, evaporative processes within the vegetated tile need to be enhanced. This in turn helps with reducing the overestimated turbulent heat flux as it reduces its vegetated value. Physically this can be seen as a way to account for processes not represented by the urban scheme such as the evaporation of water from street cleaning, fountains or any other urban sources. This approach however relies heavily on the value of the urban 
Table VII. Sensitivity of turbulent latent heat flux simulated by Noah/SLUCM.

\begin{tabular}{llccccc}
\hline & Parameter & Default & Optimum value & Gain in $Q_{\mathrm{E}}(\Delta \mathrm{RMSE})$ & Impact on $Q^{*}(\Delta \mathrm{RMSE})$ & Impact on $Q_{\mathrm{H}}(\Delta \mathrm{RMSE})$ \\
\hline 1 & $f_{\text {urb }}$ & 0.864 & 0.764 & -3.73 & -1.66 & 0.64 \\
2 & $R_{\text {cmin }}$ & 170 & 40.234 & -2.25 & 0 & -1.22 \\
3 & LAI & 3 & 4.999 & -0.76 & 0 & -0.46 \\
4 & $\alpha_{\text {veg }}$ & 0.23 & 0.102 & -0.74 & -6.36 & 1.17 \\
5 & $\Theta_{\text {ref }}$ & 0.382 & 0.284 & -0.46 & 0 & -0.21 \\
6 & $R_{\text {gl }}$ & 100 & 30.046 & -0.43 & 0 & -0.21 \\
7 & $\Theta_{\text {dry }}$ & 0.103 & 0.010 & -0.35 & 0 & -0.21 \\
8 & $f_{\mathrm{v}}$ & 0.7 & 0.800 & -0.29 & 0 & 0 \\
9 & $\Theta_{\mathrm{w}}$ & 0.103 & 0.010 & -0.13 & 0 & -0.06 \\
10 & $\Theta_{\mathrm{s}}$ & 0.465 & 0.436 & -0.09 & 0 & -0.09 \\
11 & $\varepsilon_{\text {veg }}$ & 0.93 & 0.880 & -0.08 & -0.61 & 0.04 \\
12 & $Z_{0 \text {,veg }}$ & 0.05 & 0.415 & -0.06 & 0 & 0.20 \\
13 & $h_{\mathrm{s}}$ & 39.18 & 36.262 & -0.05 & 0 & -0.04 \\
14 & $C_{\text {ZIL }}$ & 0.1 & 0.029 & -0.04 & 0 & 0.10 \\
15 & $C_{\text {soil }}$ & 1260000 & 519855 & -0.02 & 0 & 0.02 \\
16 & $\mathrm{QTZ}$ & 0.35 & 0.101 & -0.02 & 0 & 0.11 \\
\hline
\end{tabular}

The 16 parameters with the largest influence on RMSE performance, ranked based on best improvement made by a change in their default value $\left(\triangle \mathrm{RMSE} \leq 0 \mathrm{~W} \mathrm{~m}^{-2}\right)$. Impact on the RMSE of the other two modelled fluxes is also given as an indication of trade-offs.

Table VIII. Trade-off effects in the modelling of $Q_{\mathrm{E}}, Q^{*}$ and $Q_{\mathrm{H}}$.

\begin{tabular}{llcccc}
\hline & Parameter & Change in value & Gain in $Q_{\mathrm{E}}(\Delta \mathrm{RMSE})$ & Impact on $Q^{*}(\Delta \mathrm{RMSE})$ & $\operatorname{Impact}$ on $Q_{\mathrm{H}}(\Delta \mathrm{RMSE})$ \\
\hline 1 & $f_{\text {urb }}$ & 0.822 to 0.764 & -1.75 & -0.95 & 0.78 \\
2 & $\alpha_{\text {veg }}$ & 0.298 to 0.102 & -1.21 & -10.05 & 1.65 \\
3 & $C_{\text {ZIL }}$ & 0.987 to 0.029 & -0.73 & 0 & 1.01 \\
4 & $\varepsilon_{\text {veg }}$ & 0.970 to 0.880 & -0.14 & 1.10 & 0.07 \\
5 & $Z_{0, \text { veg }}$ & 0.031 to 0.415 & -0.09 & 0 & 0.27 \\
6 & $C_{\text {soil }}$ & 3929810 to 519855 & -0.07 & 0 & 0.03 \\
7 & $\Theta_{\text {ref }}$ & 0.323 to 0.284 & -0.05 & 0 & 0 \\
8 & QTZ & 0.904 to 0.101 & -0.04 & 0 & 0.39 \\
\hline
\end{tabular}

Parameters are ranked in terms of the biggest improvement in the RMSE for $Q_{\mathrm{E}}$ which can be obtained from a change of value along the Pareto front $\left(\triangle \mathrm{RMSE} \leq 0 \mathrm{~W} \mathrm{~m}^{-2}\right.$ ). The corresponding impact on the RMSE for the other fluxes is reported as a measure of the trade-off effects.

fraction (see ranking in Table VII), and for highly urbanized sites the vegetated tile might not have enough impact on the grid-averaged fluxes to balance the limitations of the urban scheme.

Figure 10 shows the diurnal mean evolution of $Q^{*}, Q_{H}$, $Q_{\mathrm{E}}$ and $\Delta Q_{\mathrm{S}}$ from a new run of Noah/SLUCM where the results from Tables $\mathrm{V}$ and VII were used as an indication of how to: (1) provide more radiative energy in the system ( $\left.\alpha_{\text {roof }}=0.15, \alpha_{\text {wall }}=0.15, \alpha_{\text {veg }}=0.19\right)$ and, (2) enhance evaporative processes from the vegetated tile $\left(R_{\mathrm{cmin}}=40.0\right.$, $\left.\mathrm{LAI}=4.0, f_{\mathrm{v}}=0.8\right)$. Note that in terms of the vegetation classification used in WRF this would represent a switch to the 'cropland/grassland mosaic' category which currently is the standard urban vegetation class in WRFv3.1. In this run we assume that the 'mixed shrub/grass' vegetation type used in the default run was restricting evaporation due to an excessive canopy resistance. A second simulation is also performed with the same settings and a value of 0.813 for the urban fraction, which represents a reduction of one standard deviation relative to its mean estimated value (Lemonsu et al., 2004). The performance of this later run is plotted (Figure 5) along with the default run to show improvements.

Copyright (C) 2010 Royal Meteorological Society and Crown Copyright.
The critical role played by the urban fraction in the partitioning of the energy between turbulent sensible and latent heat fluxes is clearly highlighted by the diurnal evolution of $Q_{\mathrm{E}}$ (Figure 10(c)). Large deviations between observed and simulated $Q_{\mathrm{E}}$ occur during night-time, even after changing the vegetation class and urban fraction. This shows the limitations of compensating with Noah for deficits in the urban scheme. During much of the night, positive $Q_{\mathrm{E}}$ were measured. Plant transpiration is negligible during the night, and even if soil evaporation could be possible, it is unlikely that soil moisture at the surface is consistently so high as to allow significant night-time fluxes (unless irrigation occurs). The fluxes could however be anthropogenic. In particular the proximity of the site to a flower market and regular street cleaning (Grimmond et al., 2004) support this. This presents a fundamental problem since it cannot be fixed with parameter choices in the Noah LSM or urban fraction. It also explains the large systematic night-time errors in $Q_{E}$, even though the model appeared to well reproduce the observed night-time $Q^{*}, Q_{H}$, and $\Delta Q_{\mathrm{s}}$.

In order to reduce such biases, a better representation of the water balance inside the urban tile is needed (e.g. Mitchell et al., 2007; Oleson et al., 2008a) and should be 
(a)

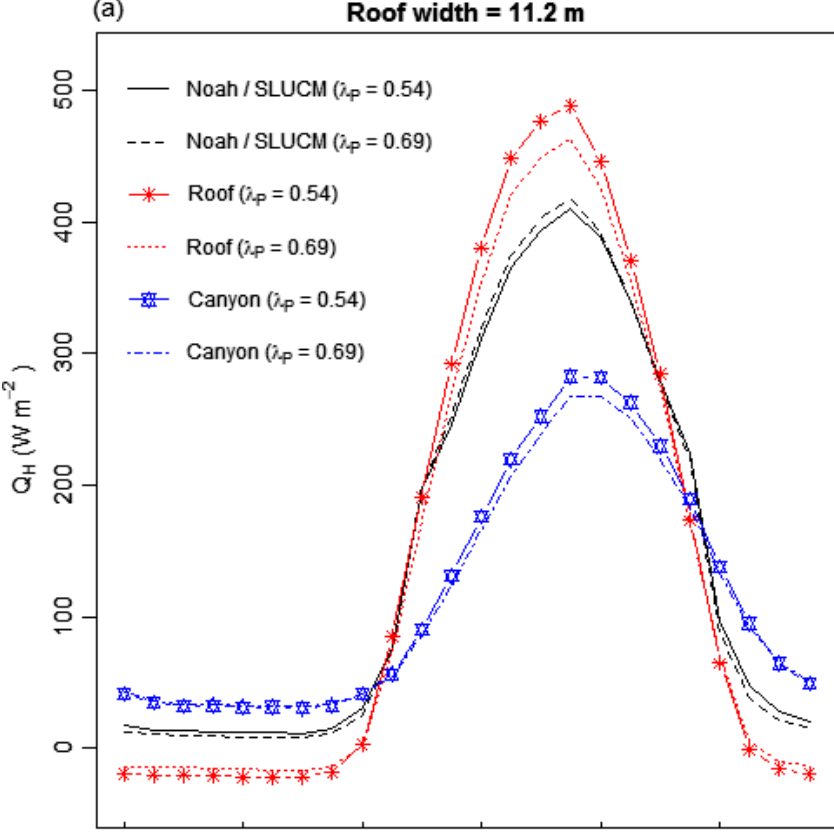

(c)

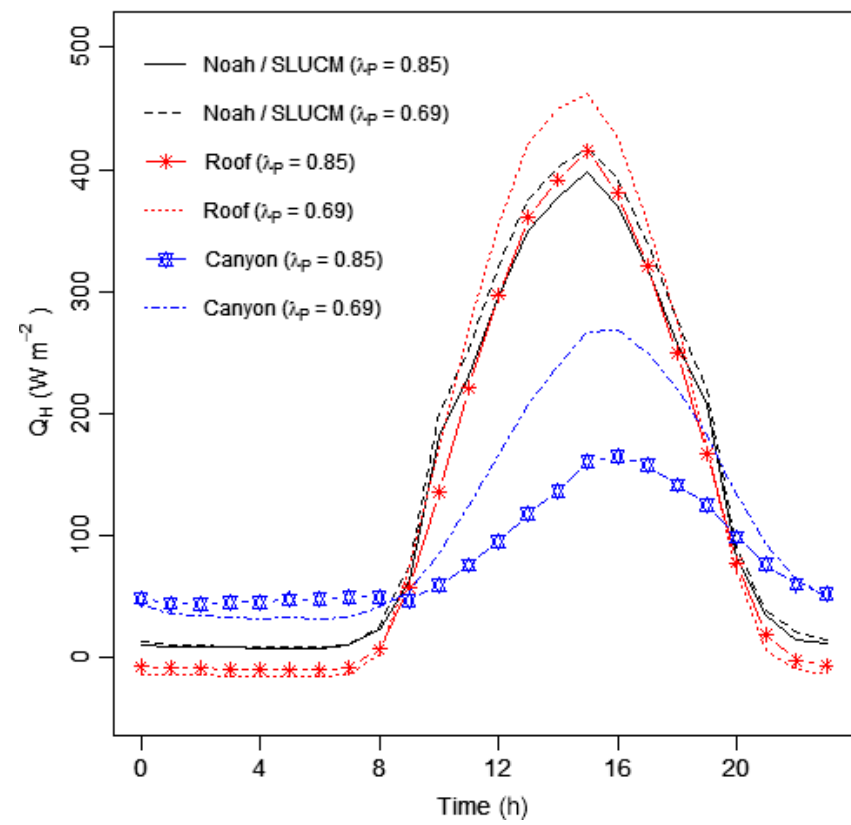

(b)

Roof width $=31.2 \mathrm{~m}$

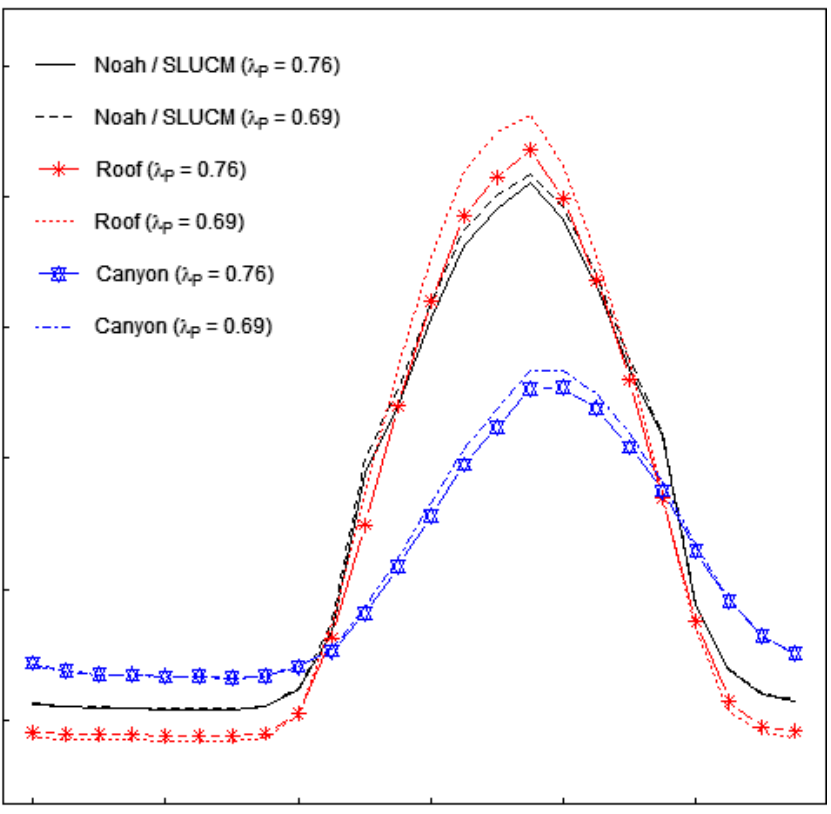

(d)

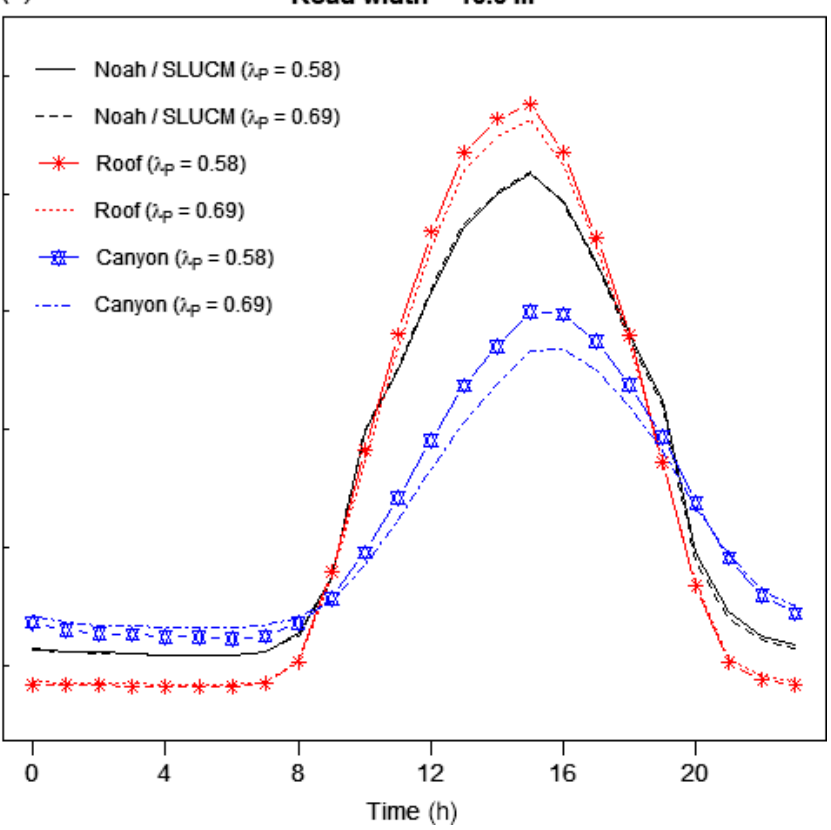

Figure 8. Impact on $Q_{\mathrm{H}}$ of (a) a $10 \mathrm{~m}$ reduction in roof width $\left(\lambda_{\mathrm{p}}=0.54\right)$, (b) a $10 \mathrm{~m}$ increase in roof width $\left(\lambda_{\mathrm{p}}=0.76\right)$, (c) a $5 \mathrm{~m}$ reduction in road width $\left(\lambda_{p}=0.85\right)$ and $(\mathrm{d})$ a $5 \mathrm{~m}$ increase in road width $\left(\lambda_{\mathrm{p}}=0.58\right)$ from the default values $\left(\lambda_{\mathrm{p}}=0.69\right)$. This figure is available in colour online at www.interscience.wiley.com/journal/qj

a priority in future developments of urban energy balance schemes.

\section{Conclusion}

A systematic and objective model response analysis method using the MOSCEM algorithm of Vrugt et al. (2003) is used to assess fitness of an urban parametrization scheme. An updated version of the parametrization implemented in WRF (Noah/SLUCM) is presented, focussing on features which improve its applicability. In particular, input parameter values with ambiguous meaning at the scale of a grid cell (e.g. $Z_{0 \mathrm{C}}, Z_{0 \mathrm{R}}$ ) have been linked to urban morphology. Using observations from Marseille the updated version of Noah/SLUCM was tested offline and compared to other similar urban canopy models. The need for an analysis of the scheme's response to its updated list of input parameters was used as a case-study to apply the procedure, and led to the ranking of all parameters in terms of their impact on the modelling of the surface energy balance fluxes.

Results with Marseille data suggest that the Noah/SLUCM scheme is most sensitive to roof-related parameters, and the associated default values to be implemented for the urban land use in WRF should therefore be derived with particular care. Albedo values represent the most critical characteristic in the modelling of $Q^{*}$ while $Q_{H}$ is mainly sensitive to roof (wall) conductivities and the thickness of roof materials. Given the unifying role they now play in the set of parametrization implemented in the SLUCM, canyon 


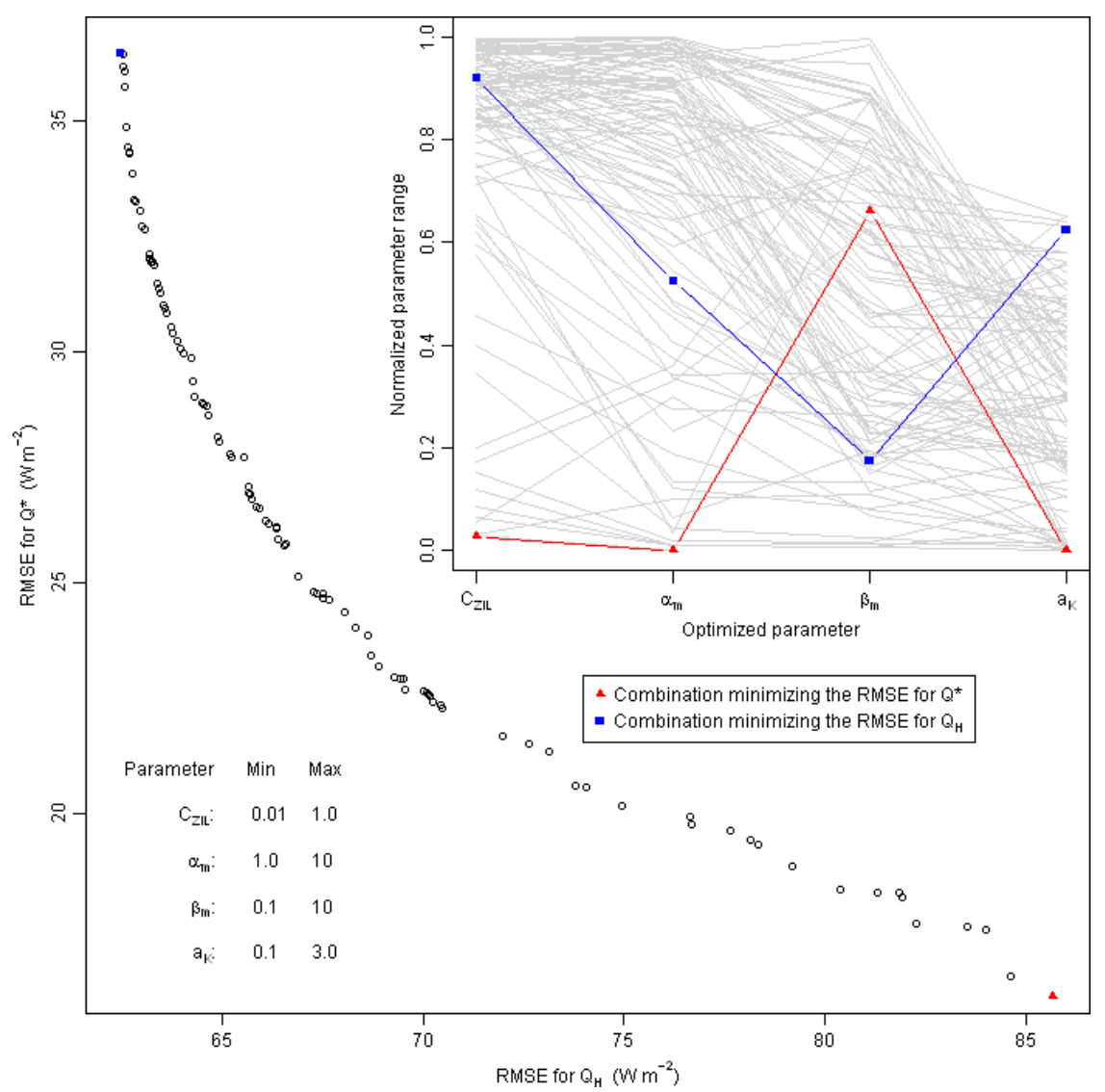

Figure 9. Multi-parameter optimization of empirical coefficients $C_{\mathrm{ZIL}}, \alpha_{\mathrm{m}}, \beta_{\mathrm{m}}$ and $a_{\mathrm{K}}$. Inset shows the 100 combinations of parameter values (normalized) selected by MOSCEM. This figure is available in colour online at www.interscience.wiley.com/journal/qj
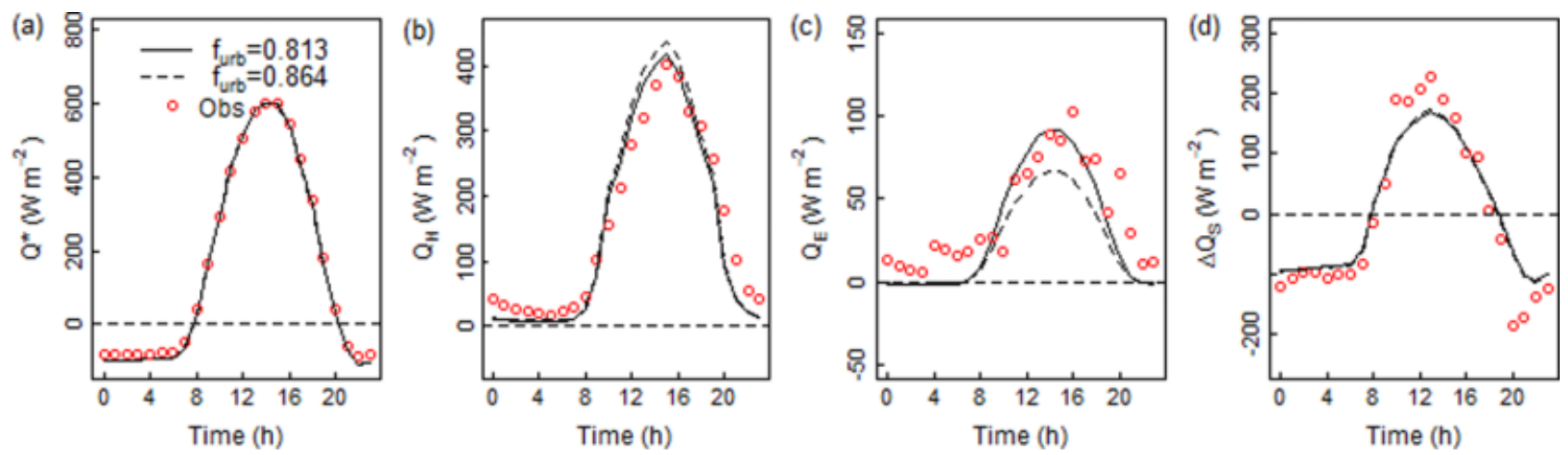

Figure 10. Diurnal mean for (a) $Q^{*}$, (b) $Q_{\mathrm{H}}$, (c) $Q_{\mathrm{E}}$ and (d) $\Delta Q_{\mathrm{S}}$ from two different runs of the Noah/SLUCM $\left(\alpha_{\text {roof }}=0.15, \alpha_{\text {wall }}=0.15, \alpha_{\text {veg }}=0.19\right.$, $\left.R_{\mathrm{cmin}}=40.0, \mathrm{LAI}=4.0, f_{\mathrm{v}}=0.8\right)$ plus $f_{\mathrm{urb}}=0.864$ (dashed) and $f_{\mathrm{urb}}=0.813$ (solid). See text for notation. This figure is available in colour online at www.interscience.wiley.com/journal/qj

geometry parameters are also of particular importance for the modelling of both fluxes. Road characteristics on the other hand do not significantly impact the model performance and a higher degree of uncertainty in their estimation can therefore be accepted.

The difficulty the scheme has in correctly partitioning turbulent energy between latent and sensible heat is highlighted. The choice of a vegetation class with a low stomatal resistance (e.g. 'cropland/grassland mosaic' or 'grassland') is recommended for urban applications in order to balance the insufficient representation of urban evaporation in the SLUCM. Further research is needed to represent the anthropogenic source of moisture, because the current approach appears limited for highly urbanized sites where the anthropogenic contribution is likely to be more important than that from natural vegetation. These results have implications for application of this type of model to consider different countermeasures to urban heat islands; such as green roofs.

This study provides some first insights into the critical parameters in the estimation of the surface energy balance for a dense European city centre such as Marseille, and suggests an approach for urban parameter optimization using field observations. The analysis however needs to be repeated with additional sites offering contrasting levels of urbanization and various climatic conditions before drawing general conclusions on the most influential parameters. That the scheme appears mostly sensitive to 'objectively determined' parameters (first category of inputs) highlights the difficulties in its implementation for NWP applications: 
since it is close to impossible to derive all needed inputs for every single urban grid cell in a particular domain, some generic urban classes are needed (e.g. urban climate zones: Oke, 2004) and the choice of model input values to best characterise each class will once again result from a trade-off. As noted (section 2), only a multi-parameter optimization of these inputs would enable identification of optimum values to be assigned for urban land-cover classes in WRF. Finally, a real-time assessment of how much the resulting flux improvements impact forecasting is needed to determine the overall fitness of the scheme for NWP. The added complexity induced by forcing the scheme from WRF rather than observations might however considerably alter its response. This offline evaluation of the Noah/SLUCM provides an objective assessment and is highly complementary to the evaluation of the coupled WRF/Noah/SLUCM modelling system (e.g. Lin et al., 2008; Miao et al., 2009).

\section{Acknowledgements}

Thanks to all those who were involved in the Marseille/ESCOMPTE field campaign, and to both Jasper A. Vrugt and Luis A. Bastidas for the development and sharing of the MOSCEM optimization software. The authors would also like to thank the reviewers for the careful review. Financial support for this project was provided by the US National Science Foundation ATM-0710631. The work conducted at NCAR was supported by the US Air Force Weather Agency (AFWA), NCAR FY07 Director Opportunity Fund, and the Defense Threat Reduction Agency (DTRA) Coastal-urban project.

\section{References}

Anderson V. 2009. 'The exacerbation of anthropogenic heat fluxes as a function of interior climate controls and building envelope.' Master's thesis, M. S. Geography, Atmospheric Science Program, Indiana University, Bloomington.

Arnfield AJ, Grimmond CSB. 1998. An urban canyon energy budget model and its application to urban storage heat flux modeling. Energy and Buildings 27: 61-68.

ASHRAE. 2005. ASHRAE handbook: 2005 fundamentals. American Society of Heating, Refrigerating and Air-conditioning Engineers: Atlanta.

Baklanov A, Ching J, Grimmond CSB, Martilli A. 2009. Model urbanization strategy: Summaries, recommandations and requirements. Pp 151-162 in Meteorological and air quality models for urban areas, Backlanov A, Grimmond CSB, Mahura A, Athanassiadou M (eds). Springer: Berlin, Heidelberg.

Best MJ. 2005. Representing urban areas within operational numerical weather prediction models. Boundary-Layer Meteorol. 114: 91-109.

Chen F, Dudhia J. 2001. Coupling an advanced land surface-hydrology model with the Penn State-NCAR MM5 modelling system. Part I: Model implementation and sensitivity. Mon. Weather Rev. 129: $569-585$.

Chen F, Zhang Y. 2009. On the coupling strength between the land surface and the atmosphere: From viewpoint of surface exchange coefficients. Geophys. Res. Lett. 36: L10404, DOI:10.1029/2009GL037980.

Chen F, Janjić Z, Mitchell K. 1997. Impact of atmospheric surfacelayer parameterizations in the new land-surface scheme of the NCEP mesoscale Eta model. Boundary-Layer Meteorol. 85: 391-421.

Chen F, Kusaka H, Tewari M, Bao J-W, Hirakuchi H. 2004. 'Utilizing the coupled WRF/LSM/urban modeling system with detailed urban classification to simulate the urban heat island phenomena over the Greater Houston area.' Paper 9.11 in Preprints, Fifth Conference on urban environment, Vancouver, BC, Canada, 23-26 August 2004. Amer. Meteorol. So.

Chen F, Kusaka H, Bornstein R, Ching J, Grimmond CSB, GrossmanClarke S, Loridan T, Manning KW, Martilli A, Miao S, Sailor D, Salamanca FP, Taha H, Tewari M, Wang X, Wyszogrodzki AA,
Zhang C. 2010. The integrated WRF/urban modelling system: Development, evaluation, and applications to urban environmental problems. Int. J. Climatol. DOI: 10.1002/joc. 2158.

Coceal O, Belcher SE. 2004. A canopy model of mean winds through urban areas. Q. J. R. Meteorol. Soc. 130: 1349-1372.

Confesor RB Jr, Whittaker GW. 2007. Automatic calibration of hydrologic models with multi-objective evolutionary algorithm and Pareto optimization. J. Amer. Water Resources Assoc. 43: 981-989.

Di Sabatino S, Solazzo E, Paradisi P, Britter R. 2008. A simple model for spatially-averaged wind profiles within and above an urban canopy. Boundary-Layer Meteorol. 127: 131-151.

Dupont S, Mestayer PG. 2006. Parameterization of the urban energy budget with the Submesoscale Soil Model. J. Appl. Meteorol. Clim. 45: $1744-1765$.

Dyer AJ, Hicks BB. 1970. Flux-gradient relationships in the constant flux layer. Q. J. R. Meteorol. Soc. 96: 715-721.

Foken T. 2008a. Micrometeorology. Springer: Berlin, Heidelberg.

Foken T. 2008b. The energy balance closure problem: An overview. Ecological Applications 18: 1351-1367.

Grimmond CSB. 2006. Progress in measuring and observing the urban atmosphere. Theor. Appl. Climatol. 84: 3-22.

Grimmond CSB, Oke TR. 1999. Aerodynamic properties of urban areas derived from analysis of surface form. J. Appl. Meteorol. 38: $1262-1292$.

Grimmond CSB, Oke TR. 2002. Turbulent heat fluxes in urban areas: Observations and a local-scale urban meteorological parameterization scheme (LUMPS). J. Appl. Meteorol. 41: 792-810.

Grimmond CSB, Salmond JA, Oke TR, Offerle B, Lemonsu A. 2004. Flux and turbulence measurements at a densely built-up site in Marseille: Heat, mass (water and carbon dioxide), and momentum. J. Geophys. Res. 109(D24): 101, DOI:10.1029/2004JD004 936.

Grimmond CSB, Blackett M, Best MJ, Barlow J, Baik J-J, Belcher SE, Bohnenstengel SI, Calmet I, Chen F, Dandou A, Fortuniak K, Gouvea ML, Hamdi R, Hendry M, Kawai T, Kawamoto Y, Kondo H, Krayenhoff ES, Lee S-H, Loridan T, Martilli A, Masson V, Miao S, Oleson K, Pigeon G, Porson A, Ryu Y-H, Salamanca F, ShashuaBar L, Steeneveld G-J, Tombrou M, Voogt J, Young D, Zhang N. 2010. The International Urban Energy Balance Models Comparison Project: First results from Phase 1. J. Appl. Meteorol. Clim., DOI: 10.1175/2010JAMC2354.1.

Gupta HV, Sorooshian S, Yapo PO. 1998. Toward improved calibration of hydrological models: Multiple and noncommensurable measures of information. Water Resour. Res. 34: 751-763.

Harman IN, Belcher SE. 2006. The surface energy balance and boundary layer over urban street canyons. Q. J. R. Meteorol. Soc. 132: 2749-2768. Inoue E. 1963. On the turbulent structure of airflow within crop canopies. J. Meteorol. Soc. Jpn 41: 317-326.

Jacobson MZ. 1999. Fundamentals of atmospheric modeling. Cambridge University Press: Cambridge, UK.

Kanda M, Kawai T, Kanega M, Moriwaki R, Narita K, Hagishima A. 2005. A simple energy balance model for regular building arrays. Boundary-Layer Meteorol. 116: 423-443.

Kanda M, Kanega M, Kawai T, Moriwaki R, Sugawara H. 2007. Roughness lengths for momentum and heat derived from outdoor urban scale models. J. Appl. Meteorol. Clim. 46: 1067-1079.

Kastner-Klein P, Rotach MW. 2004. Mean flow and turbulence characteristics in an urban roughness sublayer. Boundary-Layer Meteorol. 111: 55-84.

Kawai T, Kanda M, Narita K, Hagishima A. 2007. Validation of a numerical model for urban energy-exchange using outdoor scalemodel measurements. Int. I. Climatol. 27: 1931-1942.

Kawai T, Ridwan MK, Kanda M. 2009. Evaluation of the simple urban energy balance model using selected data from 1-yr flux observations at two cities. J. Appl. Meteorol. Clim. 48: 693-715.

Khu ST, Madsen H. 2005. Multiobjective calibration with Pareto preference ordering: An application to rainfall-runoff model calibration. Water Resour. Res. 41: W03004, DOI: 10.1029/2004WR003041.

Kondo J, Kanechika O, Yasuda N. 1978. Heat and momentum transfers under strong stability in the atmospheric surface layer. J. Atmos. Sci. 35: $1012-1021$.

Kusaka H, Kimura F. 2004. Thermal effects of urban canyon structure on the nocturnal heat island: Numerical experiment using a mesoscale model coupled with an urban canopy model. J. Appl. Meteorol. 43 : 1899-1910.

Kusaka H, Kondo H, Kikegawa Y, Kimura F. 2001. A simple singlelayer urban canopy model for atmospheric models: Comparison with multi-layer and slab models. Boundary-Layer Meteorol. 101: 329-358.

Lee X, Massman WJ, Law BE. 2004. Handbook of micrometeorology: A guide for surface flux measurement and analysis. Kluwer Academic Publishers: Dordrecht. 
Lemonsu A, Grimmond CSB, Masson V. 2004. Modeling the surface energy balance of the core of an old Mediterranean city: Marseille. J. Appl. Meteorol. 43: 312-327.

Lin C-Y, Chen F, Huang JC, Chen W-C, Liou Y-A, Chen W-N, Liu S-C. 2008. Urban heat island effect and its impact on boundary layer development and land-sea circulation over northern Taiwan. Atmos. Environ. 42: 5635-5649.

Loridan T, Grimmond CSB, Grossman-Clarke S, Chen F, Tewari M, Manning K, Martilli A. 2009. 'The Noah/Urban Canopy Model in WRF V3.1: Input parameters and sensitivity analysis using the MOSCEM optimization algorithm.' Preprints, 7th Int. Conference on urban climate, Yokohama, Japan, 29 June-3 July 2009.

MacDonald RW, Griffiths RF, Hall DJ. 1998. An improved method for estimation of surface roughness of obstacle arrays. Atmos. Environ. 32 $1857-1864$.

Martilli A, Clappier A, Rotach MW. 2002. An urban surface exchange parameterisation for mesoscale models. Boundary-Layer Meteorol. 104: $261-304$.

Masson V. 2000. A physically-based scheme for the urban energy budget in atmospheric models. Boundary-Layer Meteorol. 94: 357-397.

Masson V. 2006. Urban surface modeling and the meso-scale impact of cities. Theor. Appl. Climatol. 84: 35-45.

Masson V, Grimmond CSB, Oke TR. 2002. Evaluation of the Town Energy Balance (TEB) scheme with direct measurements from dry districts in two cities. J. Appl. Meteorol. 41: 1011-1026.

Miao S, Chen F, LeMone MA, Tewari M, Li Q, Wang Y. 2009. An observational and modeling study of characteristics of urban heat island and boundary layer structures in Beijing. J. Appl. Meteorol. Clim. 48: 484-501.

Mitchell VG, Cleugh HA, Grimmond CSB, Xu J. 2007. Linking urban water balance and energy balance models to analyse urban design options. Hydrol. Process. 22: 2891-2900.

Offerle B, Grimmond CSB, Fortuniak K. 2005. Heat storage and anthropogenic heat flux in relation to the energy balance of a central European city centre. Int. J. Climatol. 25: 1405-1419.

Offerle B, Grimmond CSB, Fortuniak K, Kłysik K, Oke TR. 2006 Temporal variations in heat fluxes over a central European city centre. Theor. Appl. Climatol. 84: 103-115.

Oke TR. 1978. Boundary layer climates. Routledge: London.

Oke TR. 2004. Initial guidance to obtain representative meteorological observations at urban sites. WMO IOM Report 81, WMO/TD 1250, 51 pp. World Meteorological Organization: Geneva.

Oleson KW, Bonan GB, Feddema J, Vertenstein M, Grimmond CSB 2008a. An urban parameterization for a global climate model. Part I: Formulation and evaluation for two cities. J. Appl. Meteorol. Clim. 47: $1038-1060$.

Oleson KW, Bonan GB, Feddema J, Vertenstein M. 2008b. An urban parameterization for a global climate model. Part II: Sensitivity to input parameters and the simulated urban heat island in offline simulations. J. Appl. Meteorol. Clim. 47: 1061-1076.

Paulson CA. 1970. The mathematical representation of wind speed and temperature profiles in the unstable atmospheric surface layer. J. Appl. Meteorol. 9: 857-861.
Pigeon G, Lemonsu A, Grimmond CSB, Durand P, Thouron O, Masson V. 2007. Divergence of turbulent fluxes in the surface layer: Case of a coastal city. Boundary-Layer Meteorol. 124: 269-290.

Rafailidis S. 1997. Influence of building areal density and roof shape on the wind characteristics above a town. Boundary-Layer Meteorol. 85: 255-271.

Ratti C, Di Sabatino S, Britter R, Brown M, Caton F, Burian S. 2002. Analysis of 3-D urban databases with respect to pollution dispersion for a number of European and American cities. Water, Air, \& Soil Pollution: Focus 2: 459-469.

Roberts SM, Oke TR, Grimmond CSB, Voogt JA. 2006. Comparison of four methods to estimate urban heat storage. J. Appl. Meteorol. Clim. 45: 1766-1781.

Roth M. 2000. Review of atmospheric turbulence over cities. Q. J. R. Meteorol. Soc. 126: 941-990.

Sellers PJ, Dorman JL. 1987. Testing the Simple Biosphere model (SiB) using point micrometeorological and biophysical data. J. Appl. Meteorol. 26: 622-651.

Shafii M, De Smedt F. 2009. Multi-objective calibration of a distributed hydrological model (WetSpa) using a genetic algorithm. Hydrol. Earth Syst. Sci. 13: 2137-2149.

Skamarock WC, Klemp JB, Dudhia J, Gill DO, Barker DM, Wang W, Powers JG. 2005. 'A description of the Advanced Research WRF Version 2.' NCAR Technical Note NCAR/TN-468+STR.

Taha H. 1999. Modifying a mesoscale meteorological model to better incorporate urban heat storage: A bulk-parameterization approach. J. Appl. Meteorol. 38: 466-473.

Voogt JA, Grimmond CSB. 2000. Modeling surface sensible heat flux using surface radiative temperatures in a simple urban area. J. Appl. Meteorol. 39: 1679-1699.

Vrugt JA, Gupta HV, Bastidas LA, Bouten W, Sorooshian S. 2003. Effective and efficient algorithm for multiobjective optimization of hydrological models. Water Resour. Res. 39(12): 14, DOI:10.1029/2002WR001746.

Willmott CJ. 1982. Some comments on the evaluation of model performance. Bull. Am. Meteorol. Soc. 63: 1309-1313.

Wilson K, Goldstein A, Falge E, Aubinet M, Baldocchi D, Berbigier P, Bernhofer C, Ceulemans R, Dolman H, Field C, Grell A, Ibrom A, Law BE, Kowalski A, Meyers T, Moncrieff J, Monson R, Oechel W, Tenhunen J, Valentini R, Verma S. 2002. Energy balance closure at FLUXNET sites. Agric. Forest Meteorol. 113: 223-243.

Xie Z-T, Coceal O, Castro IP. 2008. Large-eddy simulation of flows over random urban-like obstacles. Boundary-Layer Meteorol. 129: 1-23.

Yapo PO, Gupta HV, Sorooshian S. 1998. Multi-obective global optimization for hydrologic models. J. Hydrol. 204: 83-97.

Zilitinkevich SS. 1995. Non-local turbulent transport: Pollution dispersion aspects of coherent structure of convective flows. Pp 53-60 in Air Pollution III - Volume I: Air pollution theory and simulation, Power H, Moussiopoulos N, Brebbia CA (eds). Computational Mechanics Publications: Southampton, Boston. 